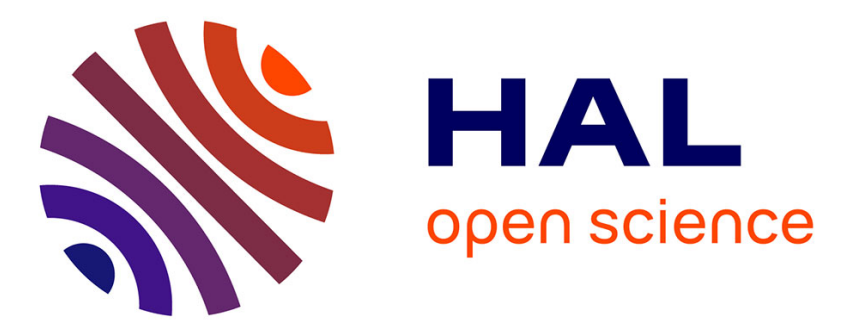

\title{
A volumetric energy based high cycle multiaxial fatigue citerion
}

\author{
Alexis Banvillet, Thierry Palin-Luc, S. Lasserre
}

\section{To cite this version:}

Alexis Banvillet, Thierry Palin-Luc, S. Lasserre. A volumetric energy based high cycle multiaxial fatigue citerion. International Journal of Fatigue, 2003, 25, pp.755-769. 10.1016/S0142-1123(03)000483. hal-01372060

\section{HAL Id: hal-01372060 https://hal.science/hal-01372060}

Submitted on 26 Sep 2016

HAL is a multi-disciplinary open access archive for the deposit and dissemination of scientific research documents, whether they are published or not. The documents may come from teaching and research institutions in France or abroad, or from public or private research centers.
L'archive ouverte pluridisciplinaire HAL, est destinée au dépôt et à la diffusion de documents scientifiques de niveau recherche, publiés ou non, émanant des établissements d'enseignement et de recherche français ou étrangers, des laboratoires publics ou privés. 


\title{
A volumetric energy based high cycle multiaxial fatigue citerion
}

\author{
A. Banvillet, T. Palin-Luc *, S. Lasserre \\ E.N.S.AM. CER de Bordeaux, Laboratoire Matériaux Endommagement Fiabilité et Ingénierie des Procédés (LAMEFIP), EA 2727, \\ Esplanade des Arts et Métiers, F-33405 Talence Cedex, France
}

\begin{abstract}
A reliable design of industrial parts against high-cycle multiaxial fatigue requires a fatigue criterion capable of predicting both th stress gradient and the load-type effects. These effects are very important in the transfer of fatigue data from specimen to component. By using the concept of volume influencing fatigue crack initiation proposed by Palin-Luc and Lasserre with an energy ba approach, a new criterion is presented. Based on the strain-work density given to the material, this proposal is usable whatever the const amplitude loading is: in and out-of-phase combined loadings, with or without mean stress. Its predictions are compared both with a tot of 38 experiments on four materials (a mild steel, two high strength steels and a spheroidal graphite cast iron) and with the predicti of local criteria (Crossland, Dang Van, Papadopoulos and Morel). The comparison shows that the predictions of the volumetric proposal very good and less scattered than those of the local approaches, especially for loadings with mean stresses or under non-proportiona loadings
\end{abstract}

Keywords: High cycle fatigue; Criterion; Multiaxial; Energy; Gradient; Volume

\section{Introduction}

Many high-cycle multiaxial fatigue criteria are proposed in the literature for metals. Four categories of fatigue criteria can be distinguished. First, until the end of the fiftie several empirical formulae were proposed to synthesize many fatigue data (Haigh, Gerber, Marin, Gough and Pollard, etc... ). Second, from the observation that after nucleation a microcrack propagates firs along a shear plane, many authors assumed that crack initiation is governed by the shear stress (McDiarmid, Findley) or by the second invariant of the deviatoric stress tensor (Sines, Crossland). Third, after the criterion proposed by Dang Van [1], other micro-macro approaches appeared (Papadopoulos, Deperrois, Morel). They consider that elastic shakedown is the condition needed to avoid fatigue crack initiation in unfavorably oriented grains. Fatigue crack initiation in polycrystalline metal is determined from the critical plane containing the easiest

\footnotetext{
* Corresponding author.

E-mail address: thierry.palin-luc@lamef.bordeaux.ensam.fr (T. Palin-Luc).
}

slip directions of the grain and experiencing the largest shear strain amplitude. Finally, some fatigue criteria are based on global energy quantities: elastic, plastic or total strain energy density. These approaches do not predict crack orientation, but the computation time of such a model is shorter than for critical plane criteria. All the above proposals are based on the stress (or strain) tensor at a critical point and none of them is able to predict the stress gradient and size effects, nor the load type effect (endurance limit in tension is not the same as in bending $[2,3])$. Furthermore the machining process also has an important effect on fatigue strength because fatigue crack nucleation depends on the finishin state of the component surface (grinding, polishing, etc...); in this paper, this "technological effect" is not considered. The surface layer and roughness of both specimen and component (with residual stresses if any) are presumed to be identical.

However, a reliable design of components against high-cycle multiaxial fatigue is still very difficul for engineers because the transfer of fatigue data from specimens to industrial parts cannot be done without considering the previous effects [4]. By analyzing fatigue data from Pogoretskii and Karpenko [5], and from Phillips 


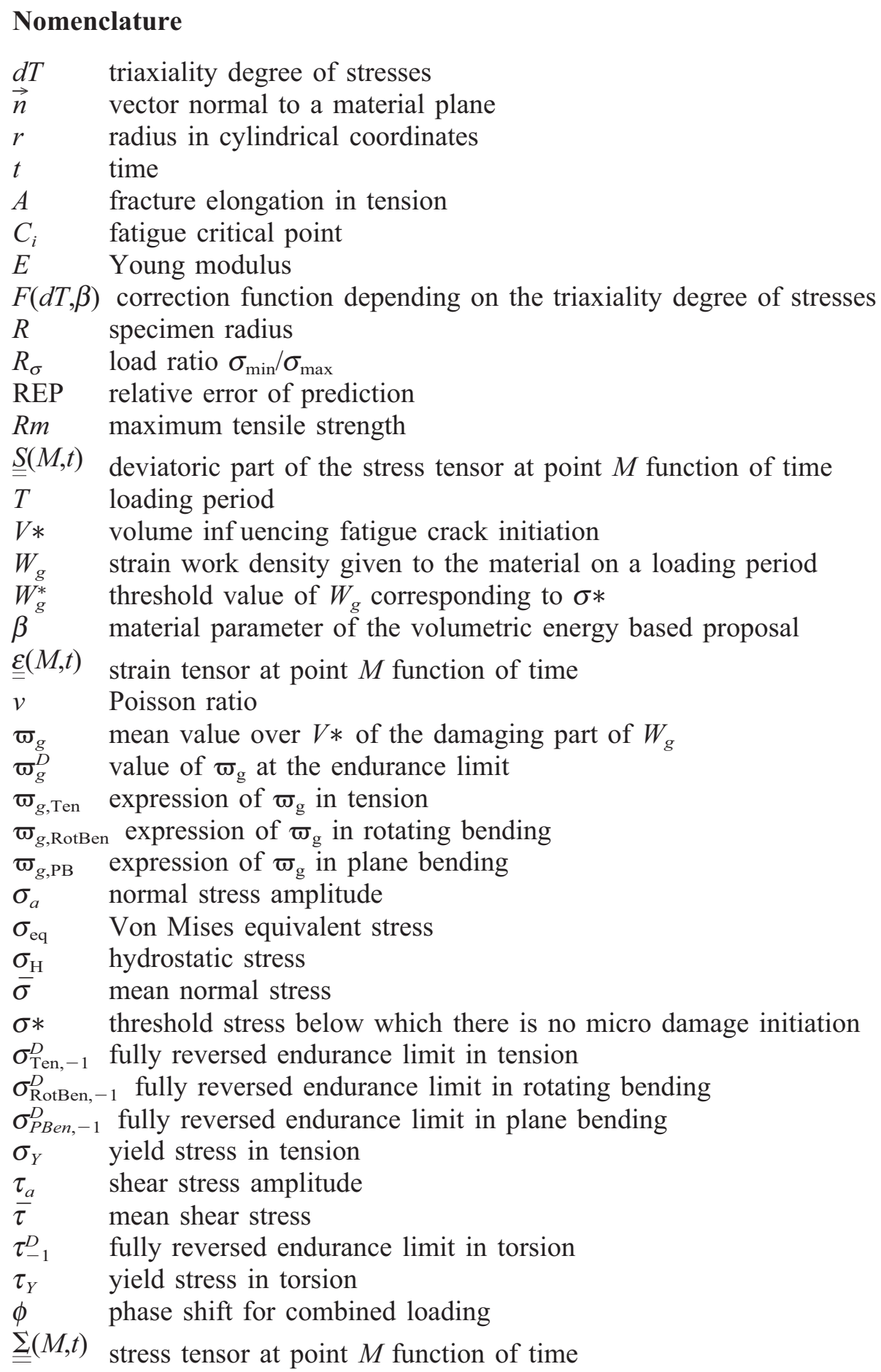

and Heywood [6], Papadopoulos et al. show that the pure gradient effect, i.e. the volumetric stress distribution effect, is more important than the pure size effect $[5,7]$. Moreover, it is not enough to characterize a notch with the theoretical stress concentration factor $K_{t}[8]$, and the fatigue notch factor $K_{f}$. For two components with different geometries these factors can be the same even if experimental fatigue limits are different [9]. All the previous fatigue criteria do not predict the pure gradient effect because they only consider stress and strain ten- sors at the critical point. This is the reason why, from about twenty years ago, a few fatigue criteria aim to model the gradient effect: the critical layer of Flavenot and Skally [10], the Papadopoulos gradient dependent fatigue criterion [11], the effective distance of Pluvinage $[9,12]$, the maximum stressed-strained volume of Sonsino [4], the volume inf uencing fatigue crack initiation proposed by Palin-Luc and Lasserre [3], and the Robert et al. gradient dependent criterion [13]. An interesting literature review of such models is presented in [14]. 
With a more general point of view, outside the feld of fatigue research, many non-local failure criteria exist (Seweryn and Mroz [15], Kennedy and Nahan [16]).

This paper presents an evolution of the energy based volumetric fatigue criterion proposed by Palin-Luc and Lasserre [3]. The threshold stress def ning the volume inf uencing fatigue crack initiation is discussed and the predictions are analyzed for proportional and non-proportional cyclic loadings, with or without mean stresses. The predictions of this proposal are presented and compared to experiments and to the predictions calculated with some local criteria. All the fatigue criteria predict the fatigue strength corresponding to fatigue crack initiation. In experiments the size of the nucleated fatigue crack is that which a fatigue testing machine can automatically detect by monitoring the specimen stiffness decreasing: about $0.5-1 \mathrm{~mm}$ in depth; crack propagation is not considered hereafter.

\section{Proposed non-local criterion}

In 1998, from experiments on a spheroidal graphite cast iron Palin-Luc and Lasserre [17] showed that a new limit $\sigma *$ can be def ned below the usual endurance limit $\sigma^{D}$. At a considered point, a stress amplitude below this new limit does not initiate observable damage at the microscale (no micro-crack). Between $\sigma *$ and $\sigma^{D}$ a stress amplitude only contributes to micro-damage initiation which could develop if, either near this point or in the course of time, there is a stress amplitude higher than the endurance limit. The usual endurance limit is a limit of no damage propagation but is not a limit of no damage initiation at the microscale. Several works proved that micro-cracks could initiate but not propagate to macro-cracks on a specimen loaded at its endurance limit. This stress limit $\sigma *$ can be estimated [3] from fatigue test results in fully reversed tension and in rotating bending by Eq. (1).

$\sigma *=\sqrt{2\left(\sigma_{\text {Ten, }-1}^{D}\right)^{2}-\left(\sigma_{\text {RotBend, }-1}^{D}\right)^{2}}$.

By using this threshold stress Palin-Luc and Lasserre [3] proposed a volumetric energy based high-cycle multiaxial fatigue criterion which is restricted to fully reversed loadings. It also has the main drawback of being loadshape dependent for uniaxial loading (sinus, triangle, square). This is not in agreement with the fatigue data of Mielke [18] and Dietmann et al. [19].

To avoid these lacks, we propose now to consider as damage parameter the strain work density given to each elementary volume of material per loading cycle, $W_{g}(2)$. This assumption is based on the hypothesis (in agreement with thermodynamics [20]) that micro-damage cannot initiate and grow, from microscale to macroscale, without giving a strain work to each elementary volume of material [21].

$$
\begin{gathered}
W_{g}(M)=\sum_{i} \sum_{j} \int_{T}<\sigma_{i j}(M, t) \dot{\varepsilon}_{i j}^{e}(M, t)>d t \\
=\int_{\varepsilon_{i j \min }}^{\varepsilon_{i j}}{ }_{\max }<\sigma_{i j}\left(\varepsilon_{i j}\right) d \varepsilon_{i j}^{e}>.
\end{gathered}
$$

where $\langle\mathrm{a}\rangle=\mathrm{a}$ if $\mathrm{a}>0$ and $\langle\mathrm{a}\rangle=0$ if $\mathrm{a} \leq 0$.

This parameter is equal to the integral over a loading cycle (of period $T$ ) of the positive part of the strain power density. It is also equal to the sum of the positive variations of the strain energy density over the loading period $T$ (Fig. 1). $W_{g}$ is calculated with the elastic strains after elastic shakedown of the material. At the endurance limit the stresses are low enough to consider that the material remains elastic at the macroscopic scale [20] after elastic shakedown. It has to be noticed that for a uniaxial stress state $W_{g}$ is not dependent on the loading shape (sinus, triangle, square, etc ...) and is mean stress dependent. This will be discussed later.

In Fig. 1 , between $t=0$ and $t_{1}$, a work is given to the material in tension; between $t_{1}$ and $t_{2}$ the material comes back to an equilibrium state (unloaded); between $t_{2}$ and $t_{3}$, a work is given in compression; f nally between $t_{3}$ and $t_{4}$ the material comes back to an unloaded state. Note that the strain-work density given by each stress and strain is summed independently, for instance in combined tension and torsion, the work given by $\sigma_{x x}$ is summed with the work given by $\tau_{x y}$ (in Eq. (2) $\Sigma_{i} \Sigma_{j}$ $\left.<\sigma_{i j}(M, t) \dot{\varepsilon}_{i j}^{e}(M, t)>\neq<\sigma_{i j}(M, t) \dot{\varepsilon}_{i j}^{e}(M, t)>\right)$. To illustrate this, let us consider a fully reversed combined tension (or bending) and torsion out-of-phase sinusoidal fatigue test with a phase shift of $90^{\circ}$, so that the ratio between the normal stress amplitude $\sigma_{a}$ and the shear stress amplitude $\tau_{a}$ is: $\sigma_{a} / \tau_{a}=\sqrt{2(1+v)}$, where $v$ is the Poisson ratio. The non-null terms of the tensor of stresses are: $\sigma_{11}(t)=\sigma_{a} \sin (\omega t)$ and $\sigma_{12}(t)=\tau_{a} \sin (\omega t+\pi / 2)$. For such a test, illustrated in Fig. 2A for $\sigma_{a}=100$ $\sqrt{2(1+v)} \mathrm{MPa}$ and $\tau_{a}=100 \mathrm{MPa}$, with a linear elastic isotropic material, the potential strain energy density is constant: $\sigma_{i j}(t) \varepsilon_{i j}(t) / 2=(1+v)\left(\tau_{a}\right)^{2} / E$ as shown in Fig. $2 \mathrm{~B}$. This is due to the fact that during the time interval when a work is given to the material in tension, the strain energy due to torsion is released, and vice versa (Fig. 2B). But, if you compute during a loading period the strain power density due to tension, $\sigma_{11}(t) \dot{\varepsilon}_{11}(t)$, and the corresponding part due to torsion, $2 \sigma_{12}(t) \dot{\varepsilon}_{12}(t)$, you can see in Fig. $2 \mathrm{C}$ that these quantities are not constant. Since we assume that a strain work has to be given to each elementary volume of material to create damage, the strain work density given to the material due to bending has to be summed with the strain work density given to the material due to torsion. This corresponds to the dashed area of the curve: strain power density versus time in Fig. 2C. 

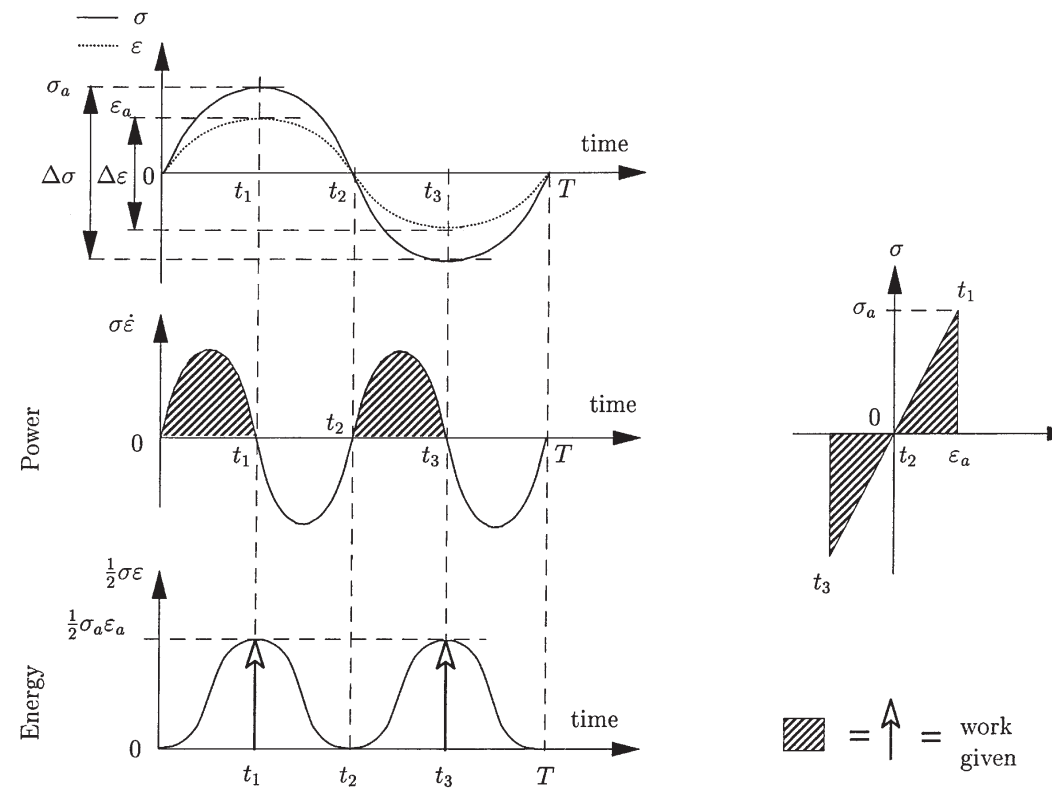

Fig. 1. Volumetric density of the elastic strain work and strain power given to the specimen on a loading period $T$ in fully reversed tension.
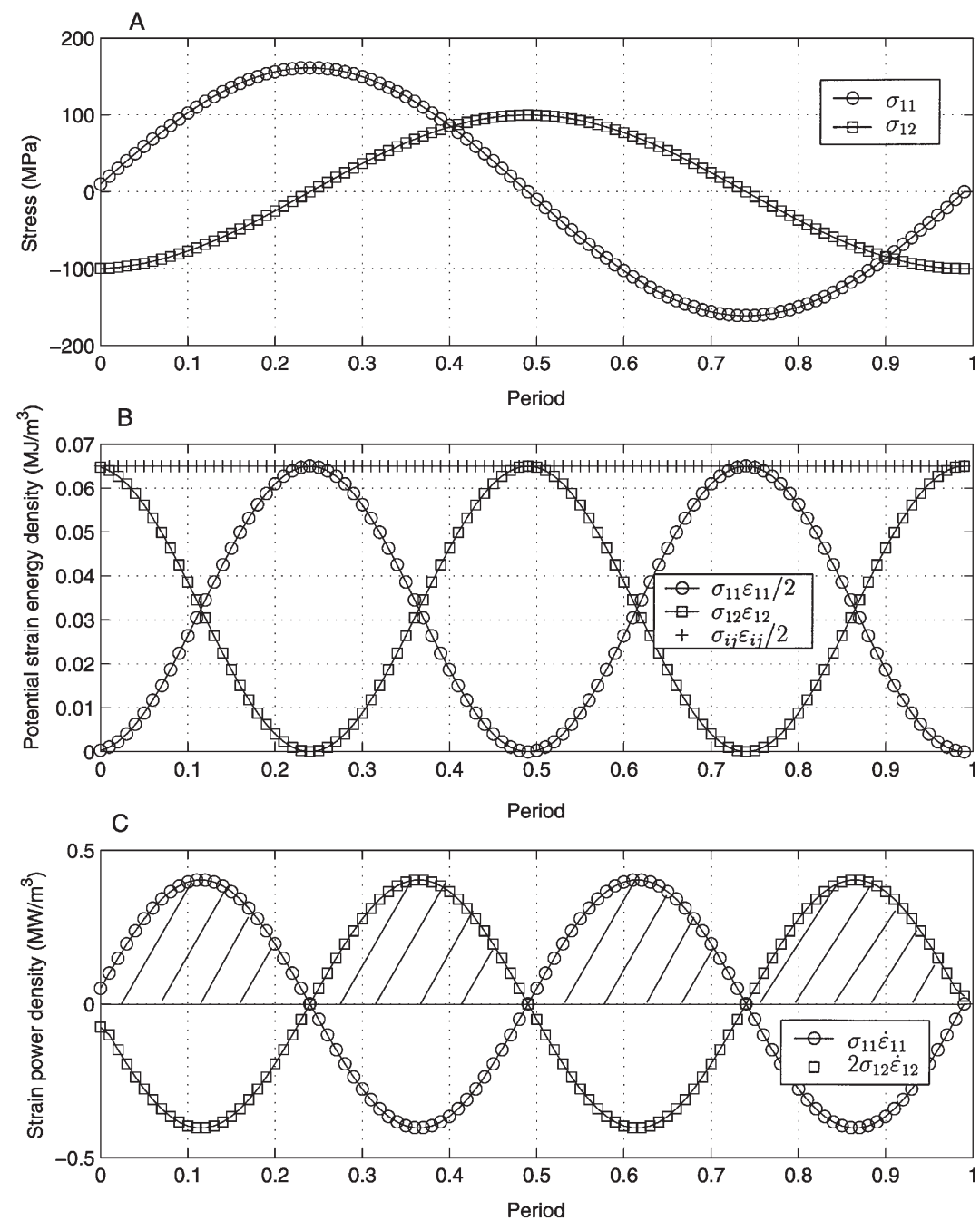

Fig. 2. Evolution versus time of the stresses (A), the potential strain energy density (B) and the strain power density (C) for a fully reversed combined tension and torsion out-of-phase sinusoidal fatigue test with a phase shift of $90^{\circ}$, so that the ratio between the normal stress amplitude $\sigma_{a}$ and the shear stress amplitude $\tau_{a}$ is: $\sigma_{a} / \tau_{a}=\sqrt{2(1+v)}$. 


\subsection{Remark about the Findley's experiment}

A well known paper by Findley [22] is often quoted in a way to debate energy based approaches in fatigue. This issue presents fatigue tests carried out on a rotating disk loaded in two perpendicular diameters by rollers. At the center of the disk, a cyclic biaxial stress state is imposed, where the non-null components of the tensor of stresses can be written as [23]: $\sigma_{11}(t)=2.9 \sigma \sin$ $(\omega t)-1.1 \sigma, \sigma_{22}(t)=2.9 \sigma \sin (\omega t-\pi)-1.1 \sigma, \sigma_{12}$ $(t)=2.9 \sigma \sin (\omega t-\pi / 2)$ where $\sigma$ is a constant proportional to the load. The amplitude of the principal stresses is constant but the principal stress directions are rotating compared with the axes $\left(\overrightarrow{x_{1}}, \overrightarrow{x_{2}}, \overrightarrow{x_{3}}\right)$ linked to the specimen. By calculating the time evolution of the potential strain energy density, $\frac{1}{2} \sigma_{i j}(t) \varepsilon_{i j}(t)$, at the center of the disk where crack appeared, the author remarked that this variable is constant during a load period though the load is cyclic. Indeed, in this case for an isotropic material with a linear elastic behaviour $\frac{1}{2} \sigma_{i j}(t) \varepsilon_{i j}(t)=$ $\frac{1}{E}\left[(1+v)(2.9 \sigma)^{2}+(1-v)(1.1 \sigma)^{2}\right]$. Since a quasi-static tension test can generate the same strain energy density without fatigue crack initiation, Findley concluded that this variable cannot be used as a damage parameter in a fatigue criterion for combined loadings.

But it has to be pointed out that Findley computed the potential strain energy density and not the strain work density given per cycle to the material. As previously explained, this work is equal to the positive variation of the strain energy density over a loading period. For the stress state of the Findley's experiment, the strain power densities corresponding to each stress and strain term of the tensor of stresses and strains are not constant, as illustrated in Fig. 3 (example with $E=200 \mathrm{GPa}, v=$ 0.3 and $\sigma=100 \mathrm{MPa}$ ). This shows that even if the potential strain energy density is constant some strain work is given to the material (it is impossible to create stresses and strains without giving a work to the material).

As proposed, by separating the strain works given by each term of the stress tensor, a non-null strain work density given to the material can be always calculated for a cyclic load. In a similar way, Park and Nelson [23] show that the distorsion work is not null for the Findley experiments.

\subsection{Volume inf uencing fatigue crack initiation}

As explained before, fatigue tests in blocks carried out on smooth specimens in spheroidal graphite (SG) cast iron, in fully reversed plane bending and torsion [24,25], prove that blocks with a stress amplitude below the conventional endurance limit and above a threshold stress

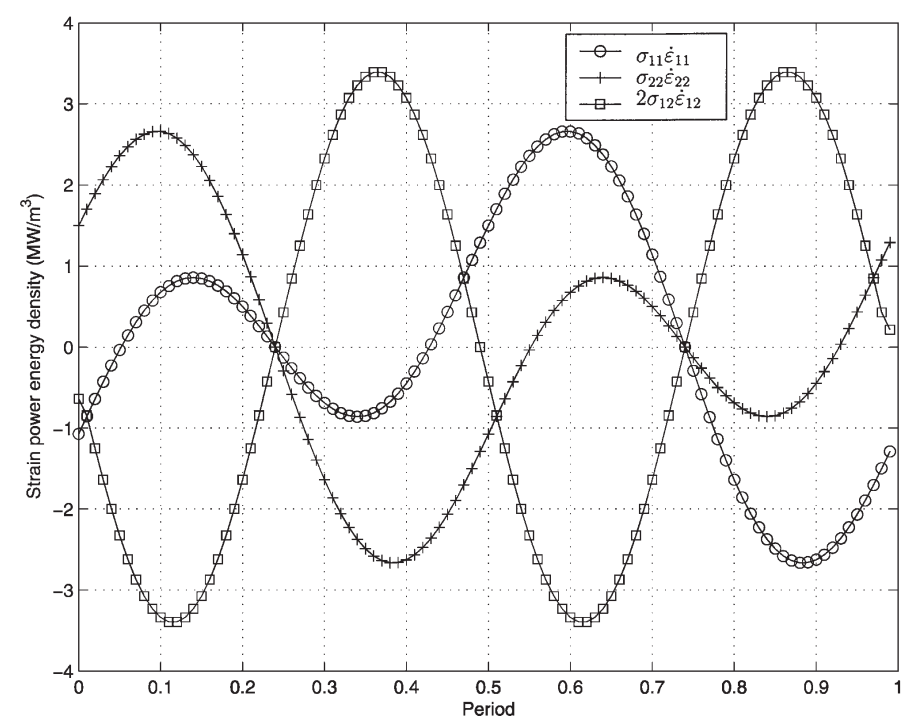

Fig. 3. Evolution of the different power strain energy densities $\sigma_{11} \dot{\varepsilon}_{11}, \sigma_{22} \dot{\varepsilon}_{22}, 2 \sigma_{12} \dot{\varepsilon}_{12}$. corresponding to each non-nul products $\sigma_{i j} \dot{\varepsilon}_{i j}$ versus time during a loading period of the Findley's experiments.

amplitude, noted $\sigma *$, participate in damage. SEM observations of a specimen loaded at a stress level higher than this limit, show quick micro-crack initiation which does not propagate if the stress amplitude stays below the usual endurance limit. More recently, sinusoidal plane bending fatigue tests were carried out on specimens with a square cross-section made in the same material. SEM observations of the specimen's lateral faces, where there is a stress gradient, show micro-damaged areas. Microcracks were observed in areas loaded at stress levels above a threshold stress which corresponds well to the threshold identif ed from experiments by blocks $\sigma *$ [21]. Then, these observations show that there is a micro-damaged volume around the fatigue critical point. With the hypothesis that all this damaged volume, noted $V *$, participates in macro-crack initiation (engineer scale), a criterion has to take into account stress and strain distribution inside this volume.

As proposed by Palin-Luc and Lasserre [3] we consider a volume inf uencing fatigue crack initiation $V *$ to predict the effects, on the fatigue strength, of the stressstrain distribution inside the component. For a fully reversed uniaxial stress state, this volume is def ned by the set of points loaded by a stress amplitude higher than a material dependent threshold stress $\sigma *$. For fully reversed sinusoidal load, ${ }^{1} W_{g}$ is proportional to the mean value of the strain energy density $W_{a}$ [21]. The threshold work $W_{g}^{*}$ corresponding to the stress limit $\sigma *$ is def ned. The stress-strain distribution effect is taken into account by computing the mean value, $\varpi_{g}$, over the volume $V *$ (4), of the strain work given to the material exceeding the threshold $W_{g}^{*}$. This is the damaging part of the strain work density given per cycle to the speci-

\footnotetext{
${ }^{1}$ Except for out of phase biaxial push-pull loads.
} 
men (3) around the critical point $C_{i}$ (where $W_{g}$ has a local maximum in the structure). The fatigue criterion is then expressed by Eq. (5) where $\varpi_{g}^{D}\left(C_{i}\right)$ is the value of $\varpi_{g}\left(C_{i}\right)$ at the endurance limit.

$\varpi_{g}\left(C_{i}\right)=\frac{1}{V *\left(C_{i}\right)} \iiint_{V *\left(C_{i}\right)}\left[W_{g}(M)-W_{g}^{*}\right] d v$.

$V *\left(C_{i}\right)$

$=\left\{\right.$ points $M(x, y, z)$ around $C_{i}$ so that

$$
\left.W_{g}(M) \geq W_{g}^{*}\right\} \text {. }
$$

$\varpi_{g}\left(C_{i}\right) \leq \varpi_{g}^{D}\left(C_{i}\right)$.

\subsection{Uniaxial stress states}

For uniaxial stress states, the hypothesis that at the endurance limit $\varpi_{g \text {,uniax }}^{D}$ is constant whatever the loading (tension, rotating bending, plane bending), $\varpi_{\text {g,uniax }}^{D}=$ $\varpi_{g, \text { Ten }}^{D}=\varpi_{g, \text { RotBen }}^{D}=\varpi_{g, \text { PB }}^{D}$, gives the relations needed to identify the thresholds $\sigma *$ and $W_{g}^{*}$ from both the fully reversed endurance limits in tension and rotating bending on smooth specimens (8). These two loadings are chosen as reference because of the same $W_{g}$ distributions on the cross-section except along the specimen radius. As there is no stress gradient along the longitudinal axis of a cylindrical smooth specimen, the volume $V *$ can be reduced to a surface $S *$ inside the cross section of the specimen (Fig. 4). Eq. (3) applied to the fully reversed tension loading becomes Eq. (6). $S *$ is all the cross-section, since all the points are loaded at the same stress level.

$\varpi_{g, \text { Ten }}^{D}=\left(\sigma_{\text {Ten },-1}^{D}\right)^{2} / E-W_{g}^{*}$.

In four point rotating bending, $S *$ is a crown between the radius $r *$ of the circle representing the iso- $W_{g}^{*}$ line, and the specimen radius $R$. Eq. (3) applied to this case becomes Eq. (7) where $(r * / R)=\sigma * / \sigma_{\text {RotBen },-1}^{D}$

$\varpi_{g, \text { RotBen }}^{D}\left(C_{i}\right)=\frac{\left(\sigma_{\text {RotBen },-1}^{D}\right)^{2}}{2 E}\left[1-(r * / R)^{2}\right]$.

From Eqs (6) and (7) the material parameters $W_{g}^{*}$ and $\sigma *$ are identif ed (8) by noting that $W_{g}^{*}=(\sigma *)^{2} / E$.

$W_{g}^{*}=\frac{2\left(\sigma_{\mathrm{Ten},-1}^{D}\right)^{2}-\left(\sigma_{\mathrm{RotBen},-1}^{D}\right)^{2}}{E}$ and

$\sigma *=\sqrt{2\left(\sigma_{\mathrm{Ten},-1}^{D}\right)^{2}-\left(\sigma_{\mathrm{RotBen},-1}^{D}\right)^{2}}$.

where $\sigma_{\mathrm{Ten},-1}^{D}$, and $\sigma_{\mathrm{RotBen},-1}^{D}$ are the endurance limits in fully reversed tension and rotating bending on a smooth specimen.

At the present stage of the model development it is assumed that the threshold work $W_{g}^{*}$ does not depend on the mean stresses. Then, the value of $\varpi_{g \text {,uniax }}^{D}$ is expressed as follows.

$\varpi_{g, \text { uniax }}^{D}=\frac{\left(\sigma_{\text {RotBen },-1}^{D}\right)^{2}-\left(\sigma_{\text {Ten },-1}^{D}\right)^{2}}{E}$.

The endurance limit can then be predicted for a cylindrical specimen loaded in four-point plane bending. Only two points are critical on the specimen cross-section where the distribution of the elastic strain work given per cycle is: $W_{g, \text { PIBen }}(M)=\frac{\left(\sigma_{\mathrm{PlBen},-1}\left(C_{i}\right)\right)^{2}}{E}\left(\frac{y}{R}\right)^{2}$.

The iso- $W_{g}^{*}$ lines are def ned by the distance $y *$ from the neutral f ber $(O, \vec{x})$. The surface $S *\left(C_{i}\right)$ around the two critical points $C_{i}$ is illustrated by Fig. 5 and def ned by Eq. (10), where $\alpha=\arcsin \left(\frac{y *}{R}\right)$.

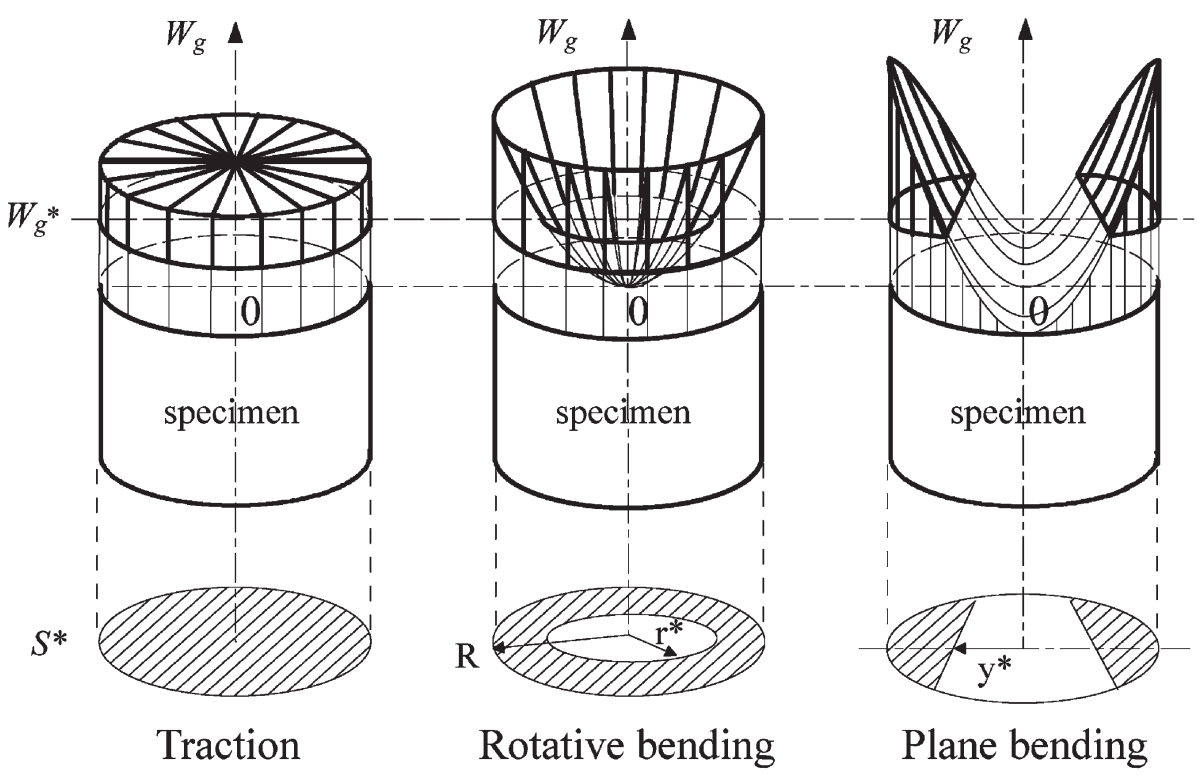

Fig. 4. Distribution of the volumetric density of the strain work given per cycle on the cross section of a smooth cylindrical specimen in tension, rotating bending and plane bending. 


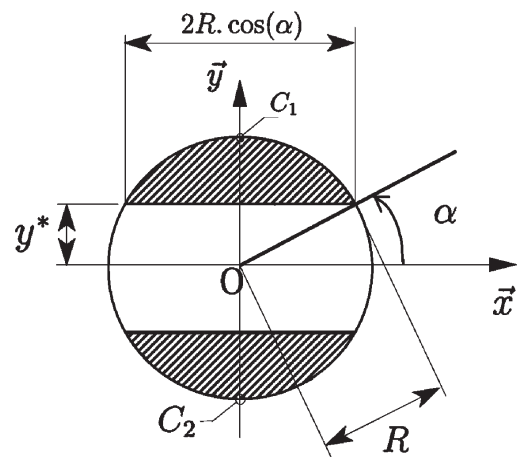

$\mathbb{Z} \mathbb{\mathbb { A }}=\triangle-\nabla-\triangle=\mathrm{S}^{*}$

Fig. 5. Surfaces $S *\left(C_{l}\right)$ and $S *\left(C_{2}\right)$ on the cross-section of a smooth specimen loaded in four point plane bending.

$\left(\frac{y *}{R}\right)^{2}=\frac{\sigma_{\mathrm{PIBen},-1}^{2}\left(C_{i}\right)}{\sigma^{* 2}}$ and

$S *\left(C_{i}\right)=\left(\pi-\frac{2 y * \cos (\alpha)}{R}-2 \alpha\right) \frac{R^{2}}{2}$.

Then, the endurance limit $\sigma_{\mathrm{PlBen}}^{D}$ is the solution of equation $\varpi_{g, \text { PIBen }}^{D}\left(C_{i}\right)=\varpi_{g, \text { uniax }}^{D}$ with,

$\varpi_{g, \text { PlBen }}^{D}\left(C_{i}\right)=\frac{\left(\sigma_{\text {Plben },-1}^{D}\left(C_{i}\right)\right)^{2}}{E}\left[A(\theta)-\theta^{2}\right]$.

where $\theta$ and $A(\theta)$ are given by Eq. (12).

$\theta=\frac{y *}{R}$ and

$A(\theta)=\frac{\frac{\pi}{8}-\frac{\theta}{4}\left(2 \theta^{2}-1\right) \sqrt{1-\theta^{2}}-\frac{\arcsin \theta}{4}}{\frac{\pi}{2}-\theta \sqrt{1-\theta^{2}}-\arcsin \theta}$.

\subsection{Multiaxial stress states}

Fatigue crack initiation depends on the triaxility of stresses. Indeed, the endurance limit in tension is not the same as in torsion, for instance. Furthermore, depending on its ductility, each material does not have the same sensitivity to the triaxiality of stresses. Thus, the material sensitivity to the triaxiality of stresses is taken into account in our proposal by using the empirical function $F$, proposed by Froustey et al. [26] and already used by Palin-Luc and Lasserre [17]. This function is def ned by Eq. (14) where $d T(M)$ is the triaxiality degree def ned by the ratio of the spherical part of the strain work given to the material $W_{g}^{s}$ over $W_{g}(13) . d T$ varies between 0 (pure torsion) and 1 (equi-axial tension or compression). $\beta$ is a material parameter. As proposed by Palin-Luc [3], this function is the ratio, at the endurance limit, of the strain work volumetric density given to the material whatever the load is, $W_{g}^{D}$, over the same value in fully reversed torsion $W_{g, \text { Tors, }-1}^{D}$

$$
\begin{aligned}
& d T(M)=\frac{W_{g}^{s}(M)}{W_{g}(M)} \text { and } W_{g}^{s}(M)=\int_{T}\left\langle\sigma_{k k} \dot{\varepsilon}_{k k}\right\rangle d t . \\
& F\left(d T\left(C_{i}\right), \beta\right)=\frac{W_{g}^{D}\left(C_{i}\right)}{W_{g, \text { Tors },-1}^{D}}=\frac{1}{1-d T\left(C_{i}\right)}\left\{1-\frac{1}{\beta} \ln [1\right. \\
& \left.\left.+\left(e^{\beta}-1\right) d T\left(C_{i}\right)\right]\right\} \text {. }
\end{aligned}
$$

The material parameter $\beta$ can be identif ed from two endurance limits under loads generating two different stress states. The fully reversed endurance limits on smooth cylindrical specimen in four point rotating bending $\sigma_{\text {RotBen, }-1}^{D}$ and in torsion $\tau_{-1}^{D}$ are recommended, because for both these loads there is only a stress gradient along the radius of the specimen. From Eq. (14) for these two loadings, $\beta$ is solution of Eq. (15) where $v$ is the Poisson ratio of the material.

$$
\begin{aligned}
& \left(\frac{\sigma_{\text {RotBen },-1}^{D}}{\tau_{-1}^{D}}\right)^{2}-3\left\{1-\frac{1}{\beta} \ln \left[1+\frac{1-2 v}{3}\left(e^{\beta}-1\right)\right]\right\} \\
& \quad=0 .
\end{aligned}
$$

For a very ductile material $\beta$ is around -1 (C20 annealed steel for instance); for a brittle one (ENGJS800-2 SG cast iron) $\beta$ is around 3 . It has to be noticed that for a ductile material $F \simeq 1$ whatever the degree of triaxiality, so the relation between the endurance limits which are predicted by the model in torsion and in rotating bending is close to the CETIM empirical proposal for steels [27]: $\tau_{-1}^{D} \approx 0.6 \times \sigma_{\text {RotBen },-1}^{D}$.

By hypothesis and as used by [3] this function $F\left(d T\left(C_{i}\right), \beta\right)$ is also used to compute the threshold strain work $W_{g}^{*}$ for different triaxiality degrees. From Eq. (14) it is easy to show Eq. (16), where $d T_{\text {uniax }}=(1-2 v) / 3$ is the triaxiality degree for a uniaxial stress state. The volume inf uencing fatigue crack initiation $V *$ is thus def ned whatever the stress state is at the critical point (17).

$W_{g}^{*}\left(C_{i}\right)=\frac{F\left(d T\left(C_{i}\right), \beta\right)}{F\left(d T_{\text {uniax }}, \beta\right)} W_{g \text {,uniax }}^{*}$.

$V *\left(C_{i}\right)=$ ppoints $M(x, y, z)$ around $C_{i}$ so that

$\left.W_{g}(M) \geq W_{g}^{*}\left(C_{i}\right)\right\}$.

Finally, it is assumed that the value of $\varpi_{g}\left(C_{i}\right)$ at the endurance limit, noted $\varpi_{g}^{D}\left(C_{i}\right)$, depends on the triaxiality degree of stresses according to Eq. (18).

$\varpi_{g}^{D}\left(C_{i}\right)=\frac{F\left(d T\left(C_{i}\right), \beta\right)}{F\left(d T_{\text {uniax }}, \beta\right)} \varpi_{g \text {,uniax }}^{D}$.

The criterion can then be applied whatever the stress state is, by comparing the value of $\varpi_{g}\left(C_{i}\right)$, see Eq. (19), and its previous limit value for the corresponding triaxility degree of stresses at $C_{i}(18)$. Fatigue crack initiates before long life if $\varpi_{g}\left(C_{i}\right) \geq \varpi_{g}^{D}\left(C_{i}\right)$. 
$\varpi_{g}\left(C_{i}\right)=\frac{1}{V *\left(C_{i}\right)} \iiint_{v *\left(C_{i}\right)}\left[W_{g}(M)-W_{g}^{*}\left(C_{i}\right)\right] d v$.

\subsection{Case study example: combined tension and torsion on smooth specimen}

To illustrate how to apply this criterion, let us study a combined tension and torsion fatigue test on a cylindrical smooth specimen with mean loads in tension $\bar{\sigma}$ and in torsion $\bar{\tau}$ so that $\sigma_{a}>\bar{\sigma}$ and $\tau_{a}>\bar{\tau}$. At the point $M(r, \theta, \phi)$ on a specimen cross-section, the tensor of stresses is given by Eq. (20) in cylindrical coordinates, where $\phi$ is the phase shift between the shear stress due to torsion and the normal stress due to tension. The distribution of the strain work density given to the material is written in Eq. (21).

$$
\begin{gathered}
\sum_{=}(M, t)=\left[\begin{array}{ccc}
0 & 0 & 0 \\
0 & 0 & {\left[\bar{\tau}+\tau_{a} \sin (\omega t+\phi)\right] \frac{r}{R}} \\
0 & {\left[\bar{\tau}+\tau_{a} \sin (\omega t+\phi)\right] \frac{r}{R}} & {\left[\bar{\sigma}+\sigma_{a} \sin (\omega t)\right]}
\end{array}\right]_{\left(\overrightarrow{e_{r}}, \overrightarrow{e_{\theta}}, \overrightarrow{e_{z}}\right)} \\
W_{g, \text { Ten+To }}(M)=\frac{\bar{\sigma}^{2}+\sigma_{a}^{2}}{E}+\frac{\bar{\tau}^{2}+\tau_{a}^{2}}{E} 2(1+v)\left(\frac{r}{R}\right)^{2} .
\end{gathered}
$$

In this equation, $R$ is the radius of the specimen and $r$ the radius at point $M$. Critical points $C_{i}$ are located at the circumference of the specimen $(r=R)$. The spherical part of the given strain work density $W_{g}^{s}$ at a critical point is:

$W_{g, \mathrm{Ten}+\mathrm{To}}^{s}\left(C_{i}\right)=\frac{1-2 v}{3 E}\left(\bar{\sigma}^{2}+\sigma_{a}^{2}\right)$.

The triaxiality degree of stresses $d T_{T e n+T o}$ at each critical point is given by Eq. (23).

$$
\begin{aligned}
& d T_{\mathrm{Ten}+\mathrm{To}}\left(C_{i}\right)=\frac{W_{g, \mathrm{Ten}+\mathrm{To}}^{s}\left(C_{i}\right)}{W_{g, \mathrm{Ten}+\mathrm{To}}\left(C_{i}\right)} \\
& \quad=\frac{1-2 v}{3}\left\{\frac{\bar{\sigma}^{2}+\sigma_{a}^{2}}{\overline{\sigma^{2}+\sigma_{a}^{2}+2(1+v)\left(\overline{\tau^{2}}+\tau_{a}^{2}\right)}}\right\} .
\end{aligned}
$$

The energy based threshold value $W_{g, \text { Ten }+ \text { To is calcu- }}^{*}$ lated from Eq. (16) and is expressed in Eq. (24).

$$
\begin{aligned}
& W_{g, \text { Ten }+\mathrm{To}}^{*}\left(C_{i}\right) \\
& =\left[\frac{2 .\left(\sigma_{\text {Ten },-1}^{D}\right)^{2}-\left(\sigma_{\text {RotBen },-1}^{D}\right)^{2}}{E}\right] \frac{F\left(d T_{\text {Ten }+\mathrm{To}}\left(C_{i}\right), \beta\right)}{F\left(d T_{\text {uniax }}, \beta\right)} .
\end{aligned}
$$

Then the volumetric mean value of the damaging strain work given to the material in the volume inf uencing fatigue crack initiation around the critical point $\varpi_{g, \text { Ten }+ \text { To }}\left(C_{i}\right)$ is computed from Eq. (19) with Eqs. (21) and (24). The following equation is obtained:

$$
\varpi_{g \mathrm{Ten}+\mathrm{To}}\left(C_{i}\right)=\frac{2(1+v)\left(\bar{\tau}^{2}+\tau_{a}^{2}\right)}{2 E}\left(1+\left(\frac{r *}{R}\right)^{2}\right)
$$

$$
+\frac{\bar{\sigma}^{2}+\sigma_{a}^{2}}{E}-W_{g \mathrm{Ten}+\mathrm{To}}^{*}\left(C_{i}\right)
$$

where the radius $r *$ limiting $V *\left(C_{i}\right)$ is solution of Eq. (26) obtained from $W_{g, T e n+T o}\left(C_{i}\right)=W_{g, T e n+T o}^{*}$. Note that $r *$ must verify $0 \leq r * \leq R$.

$$
\begin{aligned}
\left(\frac{r *}{R}\right)^{2} & \\
= & {\left[\frac{2 .\left(\sigma_{\mathrm{Ten},-1}^{D}\right)^{2}-\left(\sigma_{\mathrm{RotBen},-1}^{D}\right)^{2}}{2(1+v)\left(\bar{\tau}^{2}+\tau_{a}^{2}\right)}\right] \frac{F\left(d T_{\mathrm{Ten}+\mathrm{To}}\left(C_{i}\right), \beta\right)}{F\left(d T_{\mathrm{unia}}, \beta\right)} } \\
& -\frac{\bar{\sigma}^{2}+\sigma_{a}^{2}}{2(1+v)\left(\bar{\tau}^{2}+\tau_{a}^{2}\right)} .
\end{aligned}
$$

Then, to avoid fatigue crack initiation at the critical point, the load variables $\bar{\sigma}, \sigma_{a}, \tau$ and $\tau_{a}$ have to verify the relations (27) and (28):

$$
\begin{aligned}
& \text { If } 0<\left(\frac{r *}{R}\right)<1 \Rightarrow\left[2(1+v)\left(\bar{\tau}^{2}+\tau_{a}^{2}\right)+\bar{\sigma}^{2}\right. \\
& \begin{array}{c}
\left.(21)+\sigma_{a}^{2}\right]\left[\frac{F\left(d T_{\text {uniax }}, \beta\right)}{F\left(d T_{\text {Ten }+\mathrm{To}}\left(C_{i}\right), \beta\right)}\right]<\left(\sigma_{\text {RotBen },-1}^{D}\right)^{2} . \\
\text { If } r *=0 \Rightarrow\left[(1+v)\left(\bar{\tau}^{2}+\tau_{a}^{2}\right)+\bar{\sigma}^{2}\right. \\
\left.+\sigma_{a}^{2}\right]\left[\frac{F\left(d T_{\text {uniax }}, \beta\right)}{F\left(d T_{\text {Ten }+T o}\left(C_{i}\right), \beta\right)}\right]<\left(\sigma_{\text {Ten },-1}^{D}\right)^{2} .
\end{array}
\end{aligned}
$$

The predictions of the proposed criterion, according to Eqs (27) and (28), are illustrated in Fig. 6 for different mean stresses on a non-dimensional diagram. These predictions do not depend on the phase shift $\phi$ between ten-

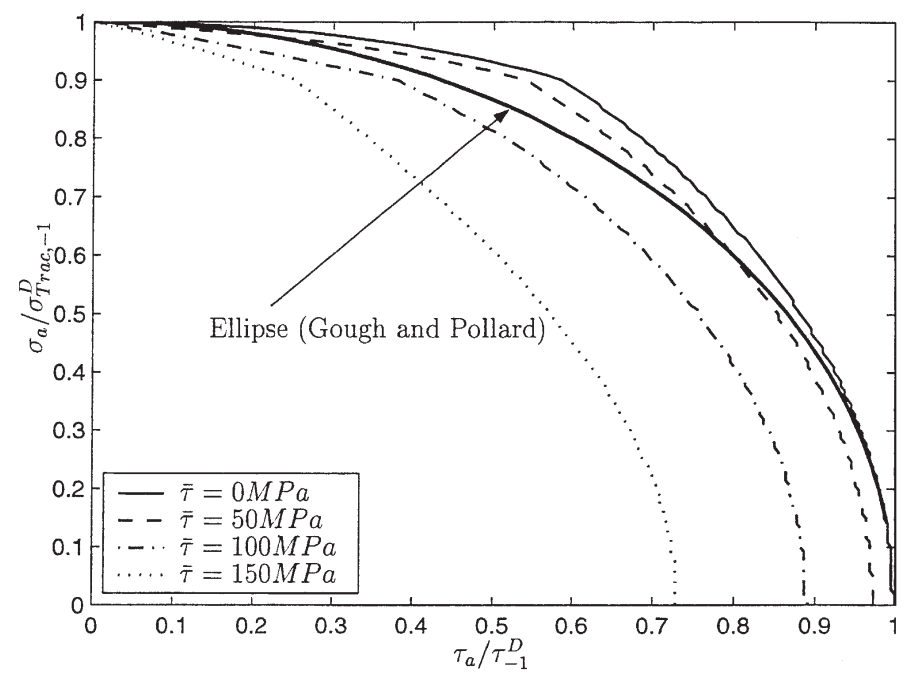

Fig. 6. Prediction of the proposal in combined tension and torsion for different mean shear stress (example for the EN-GJS800-2 SG cast iron, $\beta=3.09$ ). 
sion and torsion, which is in agreement with experimental results of the tests carried out by Simburger et al. [28] and Heidenrich et al. [29] on a middle ductile steel. For a combined loading without mean shear stress, the predictions are close to an ellipse arc similar to the Gough and Pollard proposal in combined bending and torsion. If there is no alternating shear stress, the mean shear stress inf uence on the criterion predictions is very low. This is in agreement with Froustey's experiments on the $30 \mathrm{NiCrMo} 16$ steel [30].

\subsection{Synoptic of the proposal}

The use of this criterion on an industrial component requires a f nite element analysis to compute $W_{g}$ at all the points of the component from the stress and strain time history and to compute the volume inf uencing fatigue crack initiation. For a given long time, its application can be organized as illustrated on the fow chart in Fig. 7.

\section{Discussion}

\subsection{Mean load effect}

The strain work volumetric density given per cycle to the material $W_{g}$ depends on the mean load (Fig. 8). For example, in uniaxial tension, $W_{g}(M)$ is equal to:

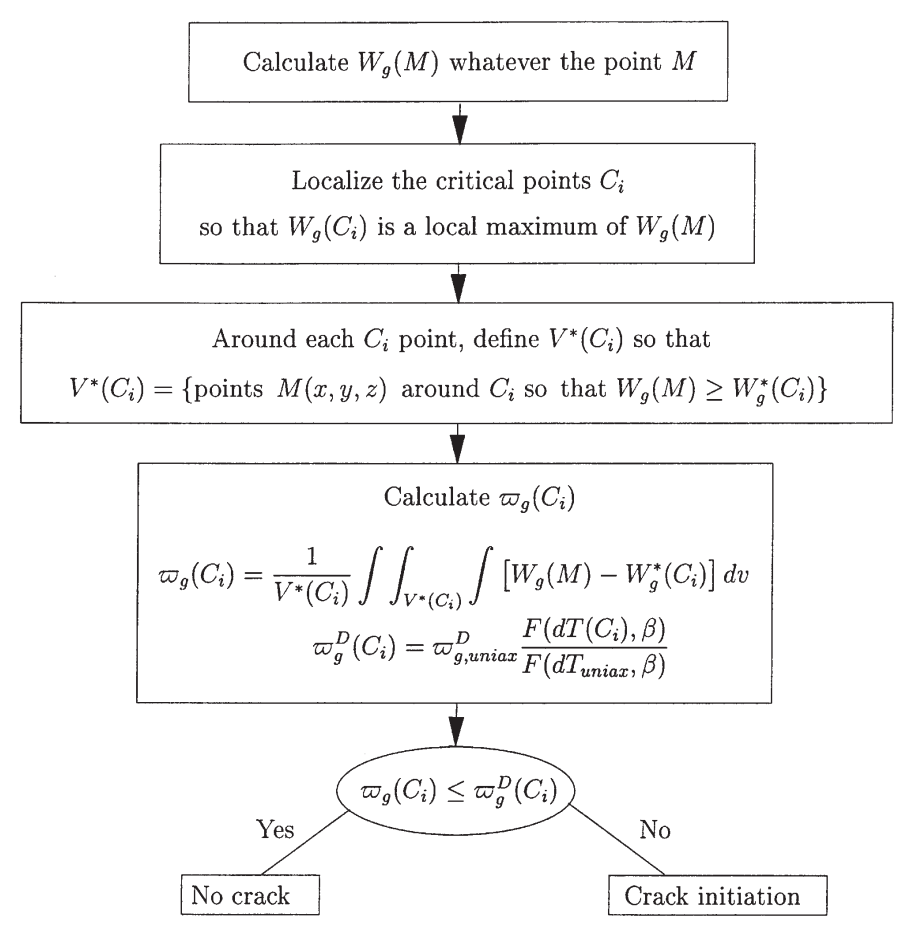

Fig. 7. Flow chart to apply the proposed non-local multiaxial fatigue criterion.
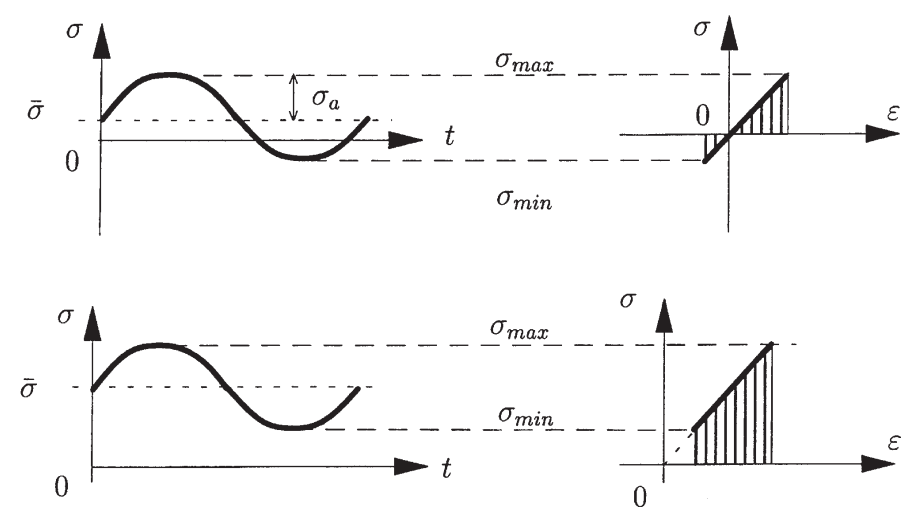

Fig. 8. Volumetric density of the elastic strain work given per cycle to the material for different mean loads in tension.

$$
\begin{aligned}
& W_{g}(M) \\
& =\left\{\begin{array}{l}
\frac{\bar{\sigma}^{2}+\sigma_{a}^{2}}{E}=\frac{\sigma_{\min }^{2}+\sigma_{\max }^{2}}{2 E} \text { if } \sigma_{a} \geq|\bar{\sigma}| \Leftrightarrow R_{\sigma} \leq 0 \\
\frac{2 \bar{\sigma} \sigma_{a}}{E}=\frac{\left|\sigma_{\min }^{2}-\sigma_{\max }^{2}\right|}{2 E} \text { if } \sigma_{a} \leq|\bar{\sigma}| \Leftrightarrow R_{\sigma} \geq 0
\end{array} .\right.
\end{aligned}
$$

In a Haigh diagram, the criterion predictions depends on the material. Fig. 9 shows these predictions for the SG cast iron (EN-GJS800-2), a middle ductile material (quenched and tempered 30NiCrMo16 steel) and a ductile material (annealed $\mathrm{C} 20$ steel). In this diagram the curve illustrating the criterion has an inf exion point. At this point the tangent line is def ned by $\sigma_{\max }=$ constant. This constant corresponds approximately to the material yield stress $\sigma_{Y}$ as shown in Fig. 9 for the $30 \mathrm{NiCrMo} 16$ steel. Thus, if the material is loaded below its yield stress, the effect of a normal mean stress on the predictions in push-pull tests is between the Goodman and the Gerber empirical criteria. This is in a good

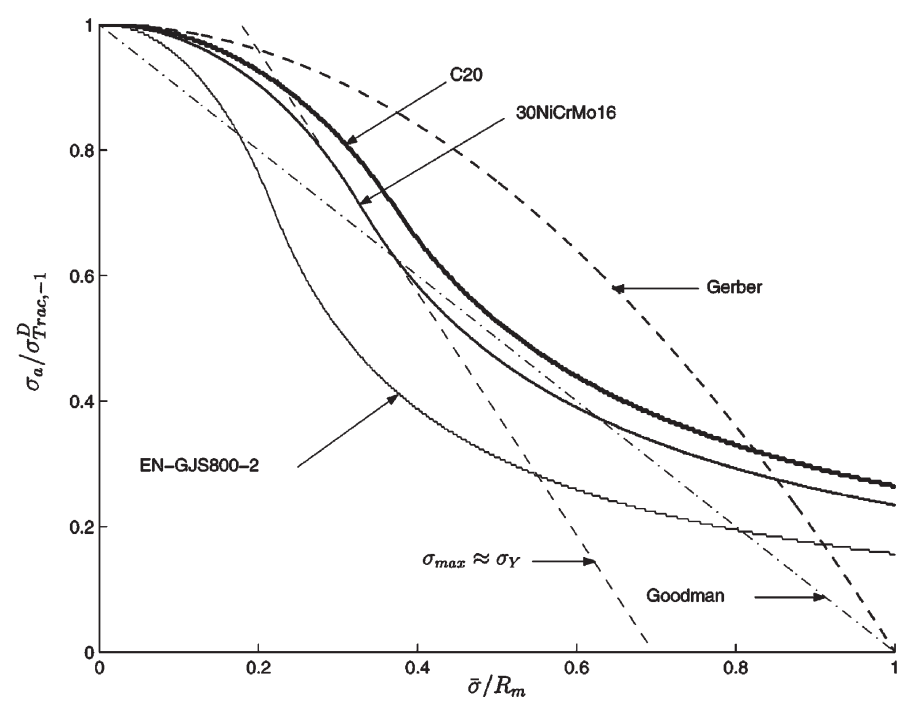

Fig. 9. Effect of mean normal stress on the criterion predictions in push-pull loadings in a Haigh diagram for three materials (example of the $\sigma_{\max } \simeq \sigma_{Y}$ line for $30 \mathrm{NiCrMo} 16$ steel). 
agreement with many fatigue data on different materials as reported by Smith [31], Sines [32] and Brand et al. [27]. These latter authors limit the Haigh diagram by a straight line def ned by $\sigma_{\max }=\sigma_{Y}$.

Fig. 10 illustrates the endurance limits predicted by the proposal in pure torsion for the $\mathrm{C} 20$ steel, the 30NiCrMo16 steel and the SG cast iron EN-GJS800-2. For these three materials the predictions are in very good agreement with the observations of Sines [32], who pointed out the low inf uence of the mean torsion load if the maximum shear stress is below the shear yield stress $\tau_{Y}$. It is also interesting to note that the predicted limit also depends on the material: the more brittle the material, the greater is the importance of its mean shear stress sensitivity. This point is conf rmed by Smith [31].

In combined plane bending and torsion the proposed criterion is close to the ellipse arc of Gough and Pollard [33] as shown in Fig. 11. It has to be pointed out that there is a very small effect, on the predicted endurance limit, of a mean shear stress without alternating shear stress. This is in agreement with Froustey's experiments in high cycle fatigue [34].

\subsection{Effect of the phase shift in combined loadings}

There is a phase shift effect on the criterion predictions in biaxial tension as shown in Fig. 12. This is in agreement with experimental results carried out by Dietman et al. [19] on a St35 steel (EN-S185). These authors showed that, for ductile materials, there is a negative effect of the phase shift on the endurance limit, whereas for brittle materials this inf uence is positive: endurance limit for out of phase loadings is greater than for loading in phase. These experimental facts are well predicted by

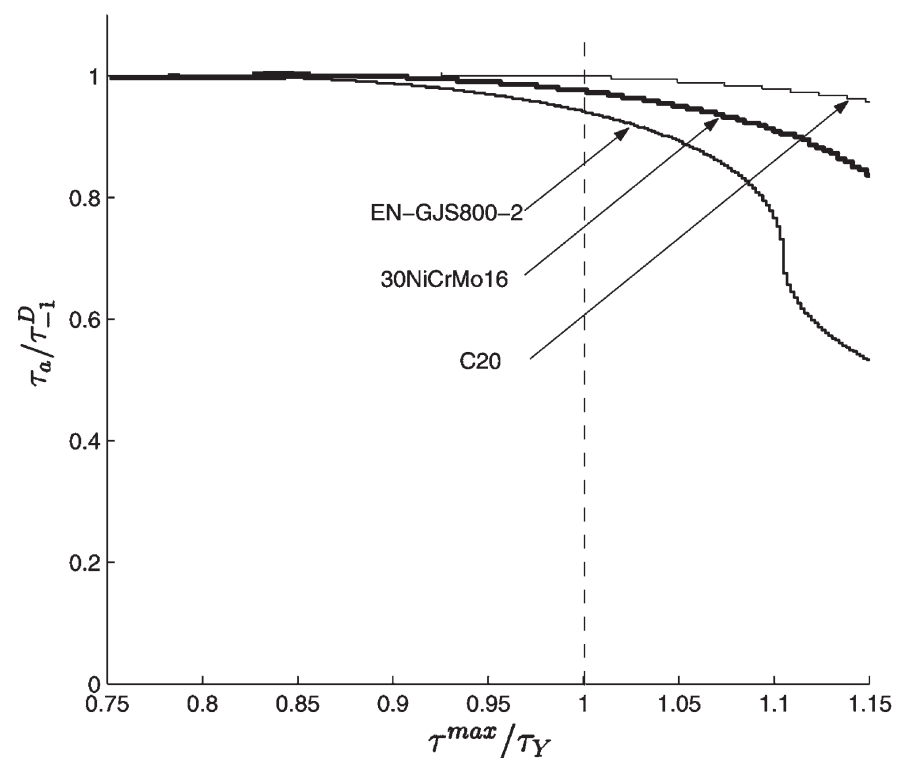

Fig. 10. Maximum shear stress inf uence on the allowable shear stress amplitude for the proposed non-local criterion (smooth specimen in torsion).

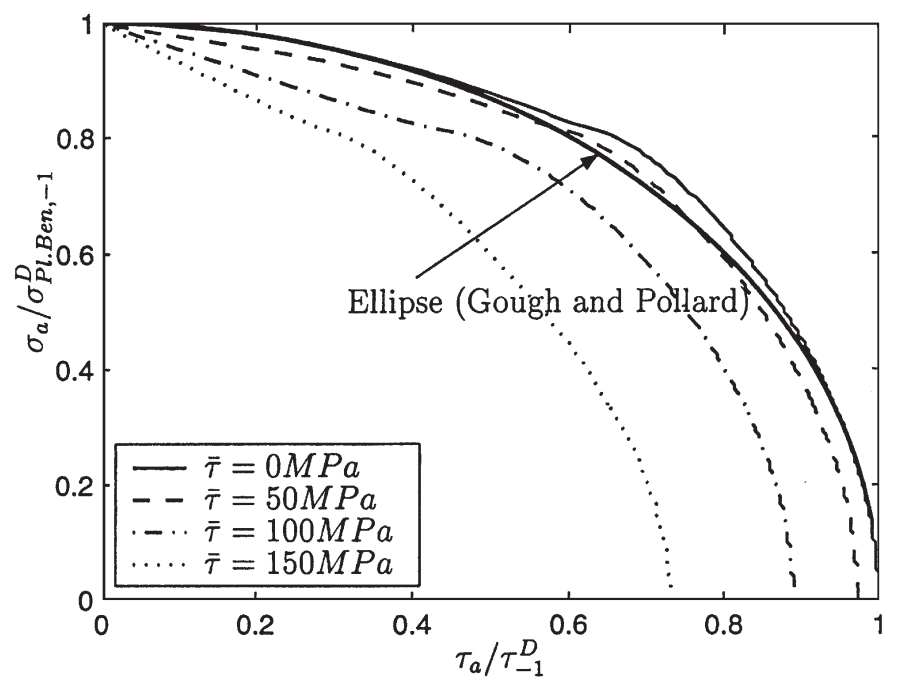

Fig. 11. Criterion predictions in combined plane bending and torsion on smooth specimen, for different mean shear stress (example for the EN-GJS800-2 SG cast iron).

our proposal, as illustrated in Fig. 12, with two types of materials: ductile and brittle. The different phase shift effects are linked with the value of the $\beta$ parameter.

On the other hand, as explained in the case study presented before, the proposal is not phase shift dependent in combined tension and torsion or bending and torsion. This point is discussed in the literature by Sonsino and Kueppers [35]. According to these authors:

- for ductile materials (structural steels, welded steels) out-of-phase loadings cause a reduction of the fatigue strength;

- for semi-ductile materials (cast steels, welded aluminum joints), the fatigue behaviour is neutral; and

- for brittle materials (cast iron, cast aluminum, sintered steels), out-of-phase loading increases the fatigue strength.

Nevertheless, this phase shift effect is small at the endurance limit (around 7\% of the endurance limit for the ENGJS800-2 SG cast iron [3]). The proposal predictions are in agreement with fatigue data in endurance if the scatter of experiments is considered $[28,34]$.

\subsection{Load type effect}

The mean value, over the volume inf uencing fatigue crack initiation, of the volumetric strain work density given to the material, $\varpi_{g}$, is load type dependent; it also depends on the specimen geometry. So this parameter is different for all the uniaxial loadings: tension, rotating bending, four-point plane bending, three-point plane bending. The criterion takes into account the stress and strain volumetric distribution around the critical point, that is why it is sensitive to the load type. As shown in Fig. 13, with an example of EN-GJS800-2 SG cast iron, 

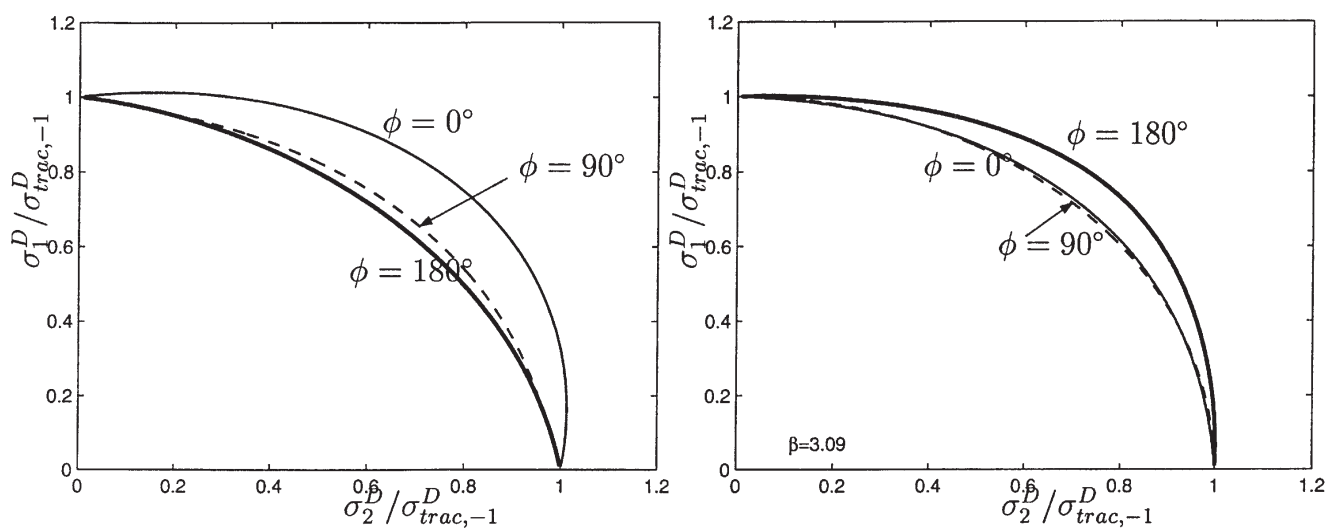

Fig. 12. Inf uence of the phase shift on the criterion prediction in biaxial tension for two materials: $35 \mathrm{CD} 4$ steel $(\beta=1.33)$ and EN-GJS800-2 SG cast iron $(\beta=3.09)$.

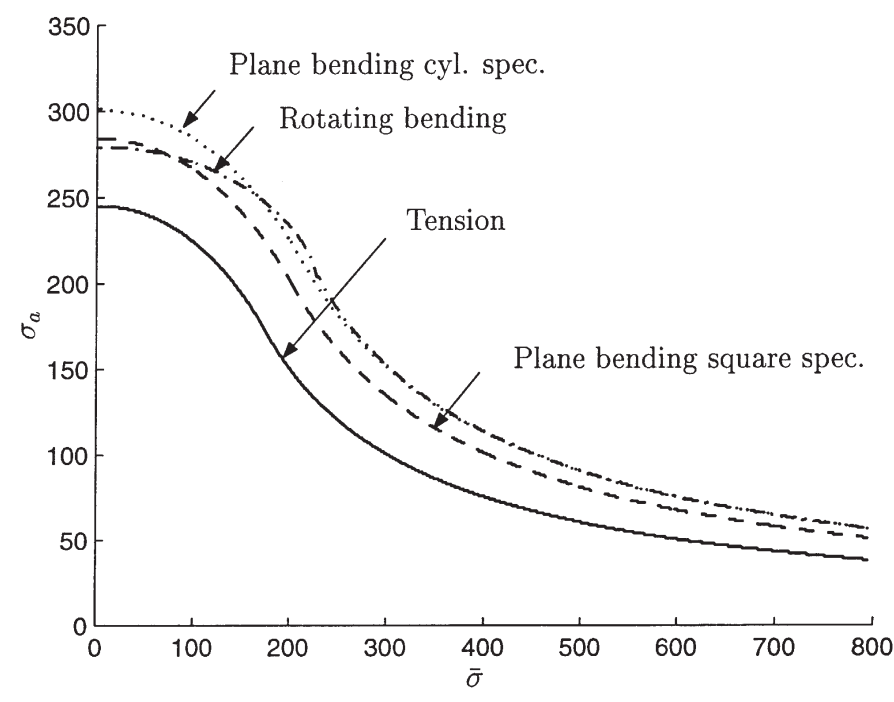

Fig. 13. Criterion predictions in a Haigh diagram in tension, plane bending on specimen with square cross section, with round cross-section and in rotating bending (example on EN-GJS800-2 cast iron).

the predictions distinguish the load type and the specimen geometry. This is in agreement with experiments [3]: the fully reversed endurance limit in tension on a smooth specimen is lower than in rotating bending; this last limit is also lower than in plane bending. Furthermore, the endurance limit in plane bending on a smooth specimen with a round cross-section is not the same as that on a smooth specimen with a square cross-section. Due to the fact that there is only a stress gradient along the radius of a round specimen loaded in rotating bending, the endurance limit in rotating bending is near the plane bending endurance limit on a specimen with square cross-section [24]. This is well predicted by our proposal as shown on the vertical axis in Fig. 13. Under combined loadings, depending on both the triaxiality degree of stresses and the material parameter $\beta$, the endurance limits predicted are also different.

\section{Comparison between predictions and experiments}

The accuracy of our proposal is compared with the accuracy of other well known local multiaxial fatigue criteria: Crossland [36], Dang-Van [37] (last proposal with double maximum on the plane orientation and in time), Papadopoulos [38] and Morel [39,40]. A short description of these models is presented in the Appendix.

The predictions of our proposal are compared with high-cycle multiaxial fatigue data $\left(10^{6}\right.$ cycles or more $)$ carried out on smooth specimens made of three materials: a quenched and tempered $30 \mathrm{NiCrMo} 16$ steel (from Froustey et al. [30]), an annealed C20 steel (from Galtier [41]) and a SG cast iron, EN-GJS800-2 (from Bennebach [42] and Palin-Luc [24]). Their main mechanical characteristics are given in Table 1; the endurance limits (at $10^{6}$ cycles or more) of this table were obtained by the stair-case method with at least 15 specimens.

The identif cation of the parameters of each criterion was done by using the endurance limits in Table 1 . These endurance limits were used to identify the parameters of our proposal $\sigma *$ and $\beta$. The value of the ratio $\sigma * /$ $\sigma_{\mathrm{Ten},-1}^{D}$ is material dependent. For the tested materials this ratio is between 0.70 and 0.90 : for the $30 \mathrm{NiCrMo} 16$ steel $\sigma *=441 \mathrm{MPa}$ and $\beta=0.96$, for $\mathrm{C} 20$ steel $\sigma *=$ $230 \mathrm{MPa}$ and $\beta \approx-1.45$, for the EN-GJS800-2 SG cast iron $\sigma *=204 \mathrm{MPa}$ and $\beta=3.09$. For the local criteria, the endurance limit in fully reversed torsion was always used as a reference. The reference uniaxial endurance limit was $\sigma_{\text {Ten, }-1}^{D}$ for the tests No. 1, 2 and 3 because these are experiments in tension; whereas for all the other tests the endurance limit in fully reversed plane bending $\sigma_{P}{ }^{\text {Ben }},-1$ was used. The $M_{\sigma}$, approach was used for the Papadoupolos criterion. For the Morel proposal, a $S-N$ curve is needed to identify the $p, q$, and $r$ parameters. The following values were dentif ed by Banvillet [21]: (i) for EN-GJS800-2: $p=70,000$ cycles, $q=$ 
Table 1

Mechanical characteristics (static and in high cycle fatigue) of the tested materials

\begin{tabular}{llllllllll}
\hline Material & $\begin{array}{l}E \\
(\mathrm{GPa})\end{array}$ & $v$ & $\begin{array}{l}\sigma_{\text {Y0.2 }} \\
(\mathrm{MPa})\end{array}$ & $\begin{array}{l}R_{m} \\
(\mathrm{MPa})\end{array}$ & $\begin{array}{l}\mathrm{A} \\
(\%)\end{array}$ & $\begin{array}{l}\tau_{-1}^{D} \\
(\mathrm{MPa})\end{array}$ & $\begin{array}{l}\sigma_{\text {Ten,-1 }}^{D} \\
(\mathrm{MPa})\end{array}$ & $\begin{array}{l}\sigma_{\text {RotBen,-1 }}^{D} \\
(\mathrm{MPa})\end{array}$ & $\begin{array}{l}\sigma_{\text {Pl.Ben,-1 }}^{D} \\
(\mathrm{MPa})\end{array}$ \\
\hline 30NiCrMo16 & 200 & 0.29 & 950 & 1200 & - & 428 & 560 & 658 \\
C20 & 210 & 0.3 & 350 & 520 & 24 & 186 & 273 & 310 \\
EN-GJS800-2 & 165 & 0.275 & 462 & 795 & 9 & 220 & 245 & 280 \\
\hline
\end{tabular}

8000 cycles and $r=0$, (ii) for C20: $p=600$ cycles, $q$ $=6000$ cycles and $r=0$, (iii) for 30NiCrMo16: $p=$ 40,000 cycles, $q=4000$ cycles and $r=0$.

A total of 38 comparisons between experiments and predictions are given in Table 2 by using the Relative Error of Pre- diction REP(\%) def ned by Eq. (30). This was computed for a given mean load and a f xed loading ratio $\sigma_{a}^{D} / \sigma_{a}^{D}$. If REP is positive, the prediction is conservative (safety), i.e. prediction is lower than experiment. If REP is negative, the prediction is unconservative (it is greater than experimental result).

Table 2

Experimental fatigue data (in MPa) and REP values (\%) for the tested fatigue criteria

\begin{tabular}{|c|c|c|c|c|c|c|c|c|c|c|c|c|}
\hline No. & Material & Load & $\sigma_{a}^{D}$ & $\bar{\sigma}^{D}$ & $\tau_{a}^{D}$ & $\bar{\tau}^{D}$ & $\phi\left(^{\circ}\right)$ & $\begin{array}{l}\text { REP }^{\mathrm{a}} \\
\text { Prop. }\end{array}$ & DV & Pap. & Cros. & Mo. \\
\hline 1 & 30NiCrMo16 & Ten & 235 & 745 & 0 & 0 & 0 & 10.2 & $-28.5^{\mathrm{b}}$ & -60.8 & -60.8 & -29.3 \\
\hline 2 & 30NiCrMo16 & Ten & 251 & 704 & 0 & 0 & 0 & 11.1 & -26.3 & -54.6 & -51 & -26.7 \\
\hline 3 & 30NiCrMo16 & Ten & 527 & 222 & 0 & 0 & 0 & 2.3 & 8.3 & 4 & 27.9 & 7.8 \\
\hline 4 & 30NiCrMo16 & P1.B & 575 & 375 & 0 & 0 & 0 & -4 & -8.8 & -18.3 & -18.3 & -9.3 \\
\hline 5 & 30NiCrMo16 & P1.B & 575 & 375 & 0 & 0 & 0 & -7.3 & -7.3 & -15.7 & -15.5 & -8 \\
\hline 6 & 30NiCrMo16 & P1.B & 627 & 273 & 0 & 0 & 0 & -6.5 & -1.6 & -7 & -7 & -2.1 \\
\hline 7 & 30NiCrMo16 & P1.B & 679 & 156 & 0 & 0 & 0 & -3.8 & 3 & 0 & 0 & 2.2 \\
\hline 8 & EN-GJS800-2 & P1.B & 184 & 225 & 0 & 0 & 0 & -10.3 & -19 & -25 & -32 & -12.5 \\
\hline 9 & 30NiCrMo16 & P1.B.+To & 519 & 0 & 291 & 0 & 0 & -8.1 & 5.4 & 2.7 & 2.7 & 4.8 \\
\hline 10 & 30NiCrMo16 & P1.B.+To & 514 & 0 & 288 & 0 & 90 & -9.1 & -36.4 & 1.7 & -34.2 & -7.6 \\
\hline 11 & 30NiCrMo16 & P1.B.+To & 451 & 294 & 250 & 191 & 0 & -3.3 & -0.4 & -9.3 & -9.3 & -1.1 \\
\hline 12 & 30NiCrMo16 & P1.B.+To & 462 & 294 & 258 & 191 & 90 & -0.4 & -39.6 & -6.3 & -45 & -10.2 \\
\hline 13 & 30NiCrMo16 & P1.B.+To & 474 & 294 & 265 & 0 & 45 & -8.4 & -3.4 & -3.6 & -11.6 & -2.3 \\
\hline 14 & 30NiCrMo16 & P1.B.+To & 464 & 294 & 259 & 0 & 60 & -10.8 & -13.15 & -5.8 & -21.1 & -8.2 \\
\hline 15 & 30NiCrMo16 & P1.B.+To & 554 & 287 & 135 & 0 & 45 & -11.9 & -9.4 & -12.1 & -15.9 & -9.4 \\
\hline 16 & 30NiCrMo16 & P1.B.+To & 474 & 0 & 265 & 0 & 90 & -18.6 & -48.1 & -6.7 & -45.6 & -16.9 \\
\hline 17 & 30NiCrMo16 & P1.B.+To & 220 & 199 & 368 & 0 & 90 & -4.5 & -6.8 & -4.1 & -10 & 0 \\
\hline 18 & 30NiCrMo16 & P1.B.+To & 470 & 299 & 261 & 0 & 90 & -9.1 & -37.4 & -4.7 & -42.5 & -8.3 \\
\hline 19 & 30NiCrMo16 & P1.B.+To & 527 & 287 & 129 & 0 & 90 & -17.6 & -20.5 & -17.8 & -27.1 & -15.6 \\
\hline 20 & 30NiCrMo16 & P1.B.+To & 433 & 472 & 240 & 0 & 90 & 2.8 & -41.6 & -11.8 & -51.7 & -11.3 \\
\hline 21 & 30NiCrMo16 & P1.B.+To & 418 & 622 & 234 & 0 & 90 & 16.7 & -38.5 & -13.4 & -54.8 & -9.3 \\
\hline 22 & 30NiCrMo16 & P1.B.+To & 0 & 299 & 396 & 0 & 0 & -7.6 & 1 & -4.8 & -4.8 & 0.5 \\
\hline 23 & 30NiCrMo16 & P1.B.+To & 0 & 486 & 411 & 0 & 0 & -3.6 & 10 & 1 & 1 & 9.5 \\
\hline 24 & 30NiCrMo16 & P1.B.+To & 0 & 655 & 364 & 0 & 0 & -17 & 4.1 & -9.9 & -9.9 & 3.6 \\
\hline 25 & 30NiCrMo16 & P1.B.+To & 482 & 0 & 268 & 0 & 0 & -16.8 & -2.7 & -5.2 & -5.2 & -2.3 \\
\hline 26 & 30NiCrMo16 & P1.B.+To & 207 & 299 & 350 & 0 & 0 & -10.1 & -1 & -9.7 & -9.7 & -1.5 \\
\hline 27 & 30NiCrMo16 & P1.B.+To & 474 & 294 & 265 & 0 & 0 & -8.4 & 4.8 & -3.6 & -3.6 & 4.2 \\
\hline 28 & 30NiCrMo16 & P1.B.+To & 584 & 281 & 142 & 0 & 0 & -6.7 & 0 & -6.3 & -6.5 & -0.7 \\
\hline 29 & 30NiCrMo16 & P1.B.+To & 447 & 473 & 252 & 0 & 0 & 6.5 & 4.9 & -7.4 & -7.4 & 4.5 \\
\hline 30 & 30NiCrMo16 & P1.B.+To & 425 & 635 & 223 & 0 & 0 & 17.9 & 1.9 & -14.6 & -14.6 & 1.4 \\
\hline 31 & $\mathrm{C} 20$ & P1.B.+To & 246 & 0 & 138 & 0 & 0 & -1.2 & 6.9 & 6.9 & 4.1 & 13.4 \\
\hline 32 & $\mathrm{C} 20$ & P1.B.+To & 264 & 0 & 148 & 0 & 90 & 5.7 & -23.1 & 1.9 & -25.4 & 8.7 \\
\hline 33 & $\mathrm{C} 20$ & P1.B.+To & 246 & 0 & 138 & 0 & 45 & -1.2 & 1.2 & 0 & -4.1 & 6.9 \\
\hline 34 & EN-GJS800-2 & P1.B.+To & 199 & 0 & 147 & 0 & 0 & -9.5 & 3 & 0.5 & 0 & 6. \\
\hline 35 & EN-GJS800-2 & P1.B.+To & 245 & 0 & 142 & 0 & 90 & 0.8 & -22 & 8.9 & -19.6 & 5.3 \\
\hline 36 & EN-GJS800-2 & P1.B.+To & 228 & 0 & 132 & 0 & 0 & -6.6 & 4.8 & 2.2 & 2.2 & 7.6 \\
\hline 37 & 30NiCrMo16 & Rot.B.+T & 337 & 0 & 328 & 0 & 0 & -8 & -4.8 & -8.3 & -8.3 & -5.3 \\
\hline 38 & 30NiCrMo16 & Rot.B.+T & 482 & 0 & 234 & 0 & 0 & -9.1 & -8.9 & -11.4 & -11.4 & -9.5 \\
\hline
\end{tabular}

a (Prop., proposal; DV., Dang Van; Pap., Papadopoulos; Cros., Crossland; Mo., Morel.

${ }^{b}$ Bold REP values are those such that $\mid$ REP $\mid \geq \pm 20 \%$. 
$\operatorname{REP}(\%)=\frac{\sigma_{a, \text { Exp }}^{D}-\sigma_{a, \text { Pred }}^{D}}{\sigma_{a, \text { Exp }}^{D}} \times 100$

In Table 2 we notice that the worst predictions are those of the local criteria of Dang Van and Crossland for nonproportional loadings and for tests with non-zero mean stress: up to a REP of $61 \%$. The scatter of the REP for the Dang Van and Crossland criteria is the largest. All the REP values are illustrated in Fig. 14. Each bar of these histograms represents the number of test conditions for which the corresponding REP value is inside a 5\% class width.

Fig. 14 shows that the REP histogram of our proposal is centered around $-5 \%$ with a shorter scatter than other tested criteria. All the endurance limits predicted by our proposal are inside the smallest scatter band: only \pm $20 \%$. Futhermore, since all the other local criteria do not distinguish tension from bending, they are very sensitive to the parameter identif cation. When a combined loading is composed with plane bending, the criterion parameters (except for our proposal) were identif ed with the endurance limit in plane bending. But, the use of the endurance limit in tension to identify material parameters of the local criteria, may generate more than $100 \%$ of REP. This may be very dangerous for a design department.

\section{Conclusion and prospects}

After a quick overview of some fatigue criteria in which predictions are stress distribution dependent, a
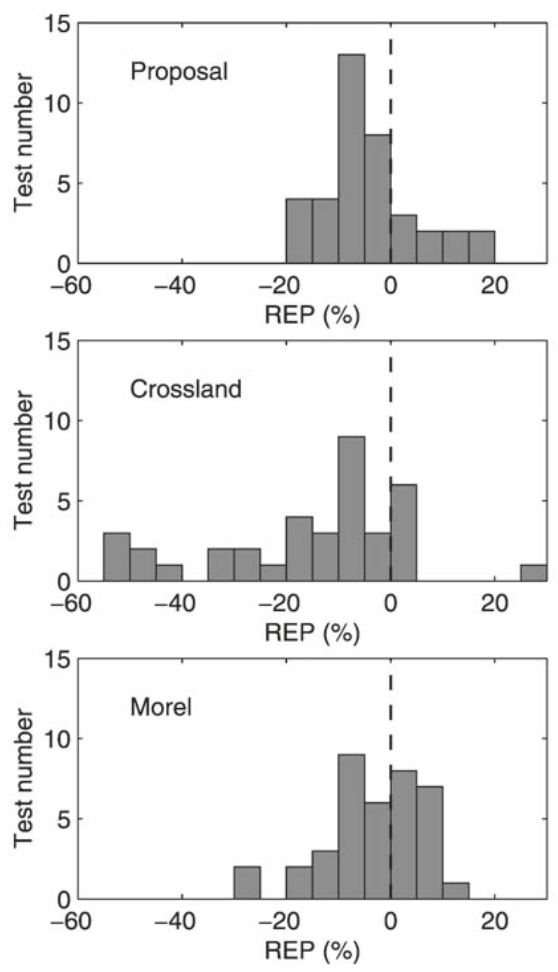

volumetric energy based high-cycle multiaxial fatigue criterion is presented. The proposal is based on the damaging part of the volumetric density of the strain work given to the material per load cycle. This is an evolution of the energy based criterion proposed by Palin-Luc and Lasserre [3] which was limited to fully reversed sinusoidal loadings. The proposal uses a non-local approach based on the concept of volume inf uencing fatigue crack initiation. This volume is limited by an energy threshold $W_{g}^{*}$ corresponding to the stress level $\sigma *$ below the usual endurance limit, above which micro-cracks can initiate in the material even if there is no macro-crack (detectable by stiffness decreasing of the specimen).

The predictions of this proposal depend on the stressstrain distribution inside the component; load types can thus be distinguished. This criterion is mean load sensitive; its predictions are in good agreement with many fatigue data from the literature. The phase shift effect on the endurance limit is also well predicted by the proposal. This effect is material dependent in biaxial tension. For a ductile material the effect is negative, but it is positive for brittle materials, as is reported in the literature. Under combined loadings, tension and torsion or bending and torsion, the criterion predictions are near the elliptic arc proposed by Gough and Pollard.

Since the volumetric stress-strain distribution is considered by the proposal, it will be interesting to test its accuracy with experiments on notched specimens. A post-processor for $\mathrm{f}$ nite element analysis is needed to compute the volume inf uencing fatigue crack initiation if the component geometry is complex. We are now
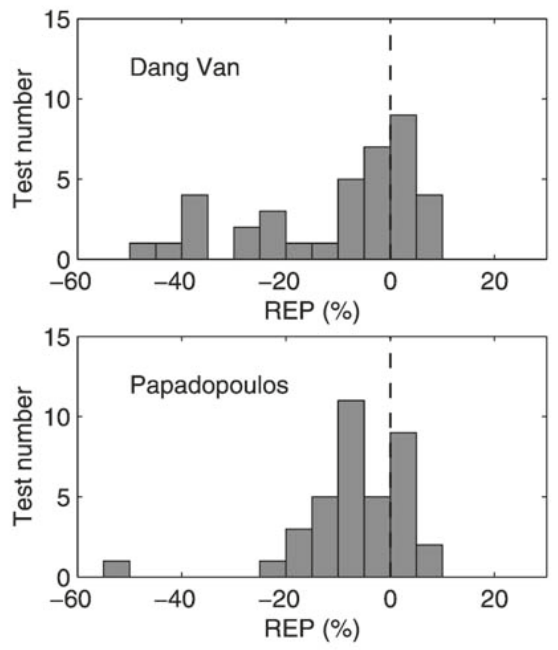

REP $>0$ Safety $R E P<0$ Unsafety

Fig. 14. Comparison of cumulative Relative Error of Prediction (\%) class width $=5 \%$. 
working on this post-processor. The energy threshold $W_{g}^{*}$ has to be correlated with micro-damage observations on different materials to understand the link between this threshold and the microstructure of the material. This proposal has also to be tested in middle cycle fatigue between $10^{5}$ cycles and more. If its predictions are good, it should be possible to predict all the $S-N$ curves from a uniaxial one since the proposal is load type and mean load sensitive.

\section{Acknowledgements}

This work was carried out as part of a research contract with the Materials Engineering Department of RENAULT. RENAULT is gratefully acknowledged for enabling the authors to do this work.

\section{Appendix: Brief description of the tested local criteria}

The Crossland criterion is def ned by a linear relationship between the maximum, on the loading period $T$, of the hydrostatic stress $\Sigma_{H, \max }$ and the amplitude $\tau_{a, J_{2}}$ of $\sqrt{J_{2}(t)}$, where $J_{2}(t)$ is the second invariant of the deviatoric stress tensor (31):

$$
\begin{aligned}
& \tau_{a, J 2}(M)=\frac{1}{2 \sqrt{2}} \max _{t^{\prime} \in T}\left\{\max _{t^{\prime} \in T}\right. \\
& \left.\left[\sqrt{\left(\underline{\underline{S}}(M, t)-\underline{\underline{S}}\left(M, t^{\prime}\right)\right):\left(\underline{\underline{S}}(M, t)-\underline{\underline{S}}\left(M, t^{\prime}\right)\right)}\right]\right\} . \\
& \tau_{a, J 2}(M)+a \Sigma_{H, \max }(M) \leq b .
\end{aligned}
$$

The material parameters $a$ and $b$ are given by the following equations: $a=\left(3 \tau_{-1}^{D} / \sigma_{-1}^{D}\right)-\sqrt{3}$ and $b=\tau_{-1}^{D}$ where $\sigma_{-1}^{D}$ is the fully reversed endurance limit for a uniaxial stress state (tension, plane bending or rotating bending) and $\tau_{-1}^{D}$ is the endurance limit in fully reversed torsion.

The Dang-Van model is a critical plane criterion based on a mesoscopic scale approach [37]. It can be expressed as Eq. (32) where $\left|\overrightarrow{\tau_{a}}(M, \vec{n}, t)\right|$ is the amplitude of the shear stress vector acting on the material plane orientated by the unit normal vector $\vec{n}$ at the point $M, \Sigma_{H}(M)$ is the hydrostatic stress. The parameters $c$ and $d$ are identif ed from two experimental endurance limits, for instance: $c=\left(3 \tau_{-1}^{D} / \sigma_{-1}^{D}\right)-(3 / 2)$ and $d=\tau_{-1}^{D}$.

$\max _{\vec{n}}\left\{\max _{t \in T}\left[\left\|\overrightarrow{\tau_{a}}(M, \vec{n}, t)\right\|+c \Sigma_{H}(M, t)\right]\right\} \leq d$.

Depending on the value of the ratio $\tau_{-1}^{D} / \sigma_{\text {Ten,-1 }}^{D}$ of the material, Papadopoulos [38] proposed two high cycle multiaxial fatigue criteria based on a mesoscopic approach. These criteria are built with two root mean square quantities. The $\mathrm{f}$ rst one, noted $T_{\sigma},(33)$, is related to the macroscopic resolved shear stress amplitude $T_{a}$ acting on all the possible directions (located by the angle $\psi$ ) of a material plane (orientated by the unit normal vector $\vec{n}$, def ned by the angles $\theta$ and $\phi$ ). The second, noted $M_{\sigma}$, is the root mean square value of $T_{\sigma}$, on all the possible material planes (34).

$$
\begin{aligned}
& T_{\sigma}(M, \theta, \phi)=\sqrt{\frac{1}{\pi} \int_{\psi=0}^{2 \pi} T_{a}^{2}(\theta, \phi, \psi) d \psi} . \\
& M_{\sigma}(M)=\sqrt{\frac{5}{8 \pi^{2}} \int_{\phi=0}^{\phi=2 \pi} \int_{\theta=0}^{\theta=\pi} T_{\sigma}^{2}(\theta, \phi) \sin \theta d \theta d \phi} .
\end{aligned}
$$

Finally, the two endurance criteria are def ned by Eqs (35) and (36). The material parameters are related, for instance, to the fully reversed endurance limits in torsion $\tau_{T o,-1}^{D}$ and in uniaxial stress state $\sigma_{-1}^{D}$ (tension, plane or rotating bending): $e=\left(3 \tau_{-1}^{D} / \sigma_{-1}^{D}\right)-(3 / 2), f=\tau_{-1}^{D}$ and $g=\left(3 \tau_{-1}^{D} / \sigma_{-1}^{D}\right)-\sqrt{3}, h=\tau_{-1}^{D}$.

If $0.5 \leq \tau_{-1}^{D} / \sigma_{\text {Ten, }-1}^{D} \leq 0.6$,

$$
\max _{\theta, \phi}\left[T_{\sigma}(M, \theta, \phi)\right]+e \Sigma_{H, \max }(M) \leq f .
$$

If $0.6 \leq \tau_{-1}^{D} / \sigma_{\text {Ten, }-1}^{D} \leq 0.8$,

$M_{\sigma}(M)+g \Sigma_{H, \max }(M) \leq h$.

Morel $[39,40]$ proposed a fatigue life calculation model based on the $T_{\sigma}$, Papadopoulos approach. The critical plane is the plane experiencing the maximum value of $T_{\sigma}$, noted $T_{\Sigma}=\max _{\theta, \phi}\left[T_{\sigma}(\theta, \phi)\right]$. According to this model, the number of cycles $N_{i}$ for fatigue crack initiation at the point $M$ is computed by the following equation for constant amplitude cyclic loadings:

$N_{i}=p \ln \left(\frac{C_{a}}{C_{a}-T_{s}}\right)+q\left(\frac{\tau_{\lim }}{C_{a}-\tau_{\lim }}\right)-\frac{r}{C_{a}}$.

where $C_{a}$ is the maximum value of the resolved shear stress amplitude $T_{a}$ on the critical plane. $\tau_{\text {lim }}$ is the limit value of the macroscopic shear stress amplitude on the critical plane (38). $\Sigma_{H, a}$ and $\Sigma_{H, m}$ are respectively the amplitude and the mean value of the hydrostatic stress, $H$ is a phase shift coeff cient: $H=T_{\Sigma} / C_{a}$, varying between $\sqrt{\pi}$ and $\sqrt{2 \pi}$.

$\tau_{\lim }=\frac{-e \Sigma_{H, m}+f}{e^{\frac{\Sigma_{H, a}}{C_{a}}+H} .}$

This author assumes that a crystal of a metallic material has a mechanical behaviour which can be described by three phases: hardening, saturation and softening. The parameters $p, q$ and $r$ are related to these phases, their identif cation is detailed in [21], [40]. Since the Morel approach is a life calculation model, its application was done by computing the endurance limit corresponding to the given long life of the reference experimental data $\left(10^{6}\right.$ cycles or more). 


\section{References}

[1] Dang Van K, Cailletaud G, Flavenot J-F, Le Douaron A, Lieurade H-P. Amorçage des f ssures de fatigue sous solicitations complexes. In: Paris: SF2M; 1984. p. 301-37.

[2] Bathias C, Baïlon J-P. La fatigue des matériaux et des structures. Paris, France: Hermès; 1997.

[3] Palin-Luc T, Lasserre S. An energy based criterion for high cycle multiaxial fatigue. Eur J Mechanis, A/Solids 1998;17(2):237-51.

[4] Sonsino CM, Kaufmann H, Gubrisic V. Transferability of material data for the example of a randomly loaded truck stub axle. SAE Tech. Paper Series (970708) 1997;1-22.

[5] Papadopoulos IV, Panoskaltsis VP. Gradient dependent multiaxial high-cycle fatigue criterion. In: Proceedings of the Fourth International Conference on Biaxial/Multiaxial Fatigue, vol. 1. St Germain en Laye, France: EF2M; 1994. p. 461-76.

[6] Phillips CE, Heywood RB. The size effect in fatigue of plain and notched steel specimens loaded under reversed direct stress. Proc I Mech E 1951;165:113.

[7] Brand A, Sutterlin R, Calcul des pieces à la fatigue-Méthode du gradient. Senlis, France: CETIM; 1980. 157 p.

[8] Peterson RE. Stress concentration factors. New York: WileyInterscience; 1974.

[9] Qylafku G, Azari Z, Kadi N, Gjonaj M, Pluvinage G. Application of a new model proposal for fatigue life prediction on notches and key-seats. Int J Fatigue 1999;21:753-60.

[10] Flavenot J-F, Skally N. L'épaisseur de couche critique ou une nouvelle approche du calcul en fatigue à long terme des structures soumises à des solicitations multiaxiales en presence de gradient de contrainte. Rev Mécanique Matériaux et Electricité 1983;397:15-25.

[11] Papadopoulos IV, Panoskaltsis VP. Invariant formulation of a gradient dependent multiaxial high-cycle fatigue criterion. Engng Fract Mech 1996;55(4):513-28.

[12] Pluvinage G. Notch effect in high cycle fatigue. In: ICF 9 Proceedings, vol. 3, 1997. p. 1237-50.

[13] Ngargueudedjim K, Weber B, Robert J-L. Accounting for stress gradient effect in multiaxial fatigue criteria. In: de Freitas M, editor. Sixth International Conference on Biaxial/Multiaxial Fatigue and Fracture. ESIS; 2001. p. 143-50.

[14] Morel F, Palin-Luc T. A non-local theory devoted to high cycle multiaxial fatigue. Int J Fatigue 2002;25:649-65.

[15] Seweryn A, Mroz Z. On the criterion of damage evolution for variable multiaxial stress states. Int $\mathrm{J}$ Solids Structures 1998;35(14):1589-616.

[16] Kennedy TC, Nahan MF. A simple nonlocal damage model for predicting failure in a composite shell containing a crack. Compos Struct 1997;39(1-2):85-91.

[17] Palin-Luc T, Lasserre S, Bérard J-Y. Experimental investigation on the signif cance of the conventional endurance limit of a spheroidal graphite case iron. Fatigue Fract Engng Mater Struct 1998;21(3):192-200.

[18] Mielke S. Festigkeitsverhalten metallischer werkstoffe unter zweiachsig-schwingender beanspruchung mit verschiedenen spannungszeitverlaufen. PhD thesis. Aachen; 1980. p. 89

[19] Dietmann H, Bonghibhat T, Schmid A. Multiaxial fatigue behavior of steels under in-phase and out-of-phase loading including different wave forms and frequencies. In: Third International Conference on Biaxial/Multiaxial Fatigue. Stuttgart; April 1989. p. 1-17.

[20] Lemaitre J, Chaboche J-L. Mécanique des matériaux solides. Paris: Bordas; 1988.

[21] Banvillet A. Prévision de durée de vie en fatigue multiaxiale sous chargements reels: vers des essais accélérés. PhD thesis. ENSAM CER de Bordeaux, France; 2001. p. 204.

[22] Findley WN, Mathur PN, Szczepanski E, Temel AO. Energy ver- sus stress theories for combined stress-A fatigue experiment using a rotating disk. J Basic Eng 1961;83(1):10-4.

[23] Park J, Nelson D. Evaluation of an energy-based approach and a critical plan approach for predicting constant amplitude multiaxial fatigue life. Int J Fatigue 2000;22:23-39.

[24] Palin-Luc T. Fatigue multiaxiale d'une fonte GS sous solicitations combinées d'amplitude variable. PhD thesis. ENSAM CER de Bordeaux, France; 1996. 261 p.

[25] Bonnafe A. Validation d'une limite de non propagation de f ssure inférieure à la limite d'endurance conventionnelle d'une fonte GS. Master's thesis. ENSAM CER de Bordeaux; 1998. p. 30.

[26] Froustey C, Lasserre S, Dubar L. Essais de fatigue multiaxiaux et par blocs, validation d'un critère pour les matériaux métalliques. In: Castex L, Pluvinage G, Vincent L, editors. Mat-Tec 92, Technology transfer series, promenade A. Ballu, F-93460 Gournay-sur-Marne, France: IITT International; 1992. p. 79$85,94$.

[27] Brand A, Flavenot J-F, Grégoire R, Tournier. Recueil de données techologiques sur la fatigue. Senlis, France: CETIM; 1980.

[28] Simbürger A. Festigkeitsverhalten zäher werkstoffe bei einer mehrachsigen, phasenverschobenen schwingbeanspruchung mit körperfesten und veränderlichen hauptspannungsrichtungen. Technical Report FB-121, Laboratorium für betriebsfestigkeit, Darmstadt, Germany: Bericht; 1975. 89 p.

[29] Heidenreich R, Richter I, Zenner H. Schubspannungsintensitatshypothesewetere experimentelle und theorestiche untersuchungen. Konstructin 1984;3(36):99-104.

[30] Froustey C, Lasserre S, Dubar L. Validité des critéres de fatigue multiaxiale à l'endurance en f exion-torsion. In: Fatigue des structures industrielles. 40 promenade Marx-Dormoy, F-93460 Gournay-sur-Marne, France: IITT International; 1989. p. 126-38.

[31] Smith JO. The effects of range of stress on fatigue strength of metals. Engineering Experiment Station, Bulletin 334 1942;39(26):52.

[32] Sines GB. Behavior of metals under complex static and alternating stresses. New York: McGraw-Hill; 1959.

[33] Gough HJ, Pollard HV, Glenshaw WJ. Some experiments on the resistance of metals to fatigue under combined stresses. Aeronaut. Research council reports and memoranda, 1951. $141 \mathrm{p}$.

[34] Froustey C. Fatigue multiaxial en endurance de l'Acier 30NCD16. PhD thesis. ENSAM CER de Bordeaux, France; 1987. $131 \mathrm{p}$.

[35] Sonsino CM, Kuepper M. Fatigue behaviour of welded aluminium under multiaxial loading. In: Sixth International Conference on Biaxial/Multiaxial Fatigue and Fracture. ESIS; 2001. p. $57-64$.

[36] Crossland B. Effect of a large hydrostatic pressure on the torsional fatigue strength of an alloy steel. In: International Conference on Fatigue of Metals. London; 1959. p. 138-49.

[37] Dang-Van K, Cailletaud G, Flavenot J-F, Le Douaron A, Lieurade H-P, Criterion for high-cycle fatigue failure under multiaxial loading. In: Brown MW, Miller KJ, editors. Biaxial and Multiaxial Fatigue. London, UK: EGF3, MEP; 1989. p. 459-78.

[38] Papadopoulos IV, Davoli P, Gorla C, Filippini M, Bernasconi A. A comparative study of multiaxial high-cycle fatigue criteria for metals. Int J Fatigue 1997;19(3):219-35.

[39] Morel F. Fatigue multiaxiale sous chargement d'amplitude variable. PhD thesis. ENSMA de Poitiers, France; 1996. 210 p.

[40] Morel F. A fatigue life prediction method based on a mesoscopic approach in constant amplitude multiaxial loading. Fatigue Fract Engng Mater Struct 1998;21:241-56.

[41] Galtier A. Contribution à l'étude de l'endommagement des aciers sous solicitations uni ou multiaxials. PhD thesis. ENSAM CER de Bordeaux, France; 1993. 193 p.

[42] Bennebach M. Fatigue d'une fonte GS. Inf uence de l'entaille et d'un traitement de surface. PhD thesis. ENSAM CER de Bordeaux, France; 1993. 157 p. 


\section{volumetric energy based high cycle multiaxial fatigue criterio}

Alexis BANVILLET, Thierry PALIN-LUC* and Serge LASSERRE

\section{ERRATA}

\section{Triaxiality degree definition}

In the published paper in International Journal of Fatigue (2003) Equation (13) is:

$$
d T(M)=\frac{W_{g}^{s}(M)}{W_{g}(M)} \text { and } W_{g}^{s}(M)=\int_{T}\left\langle\sigma_{k k} \dot{\varepsilon}_{k k}\right\rangle d t
$$

In fact, the GOOD equation is

$$
d T(M)=\frac{W_{g}^{s}(M)}{W_{g}(M)} \text { and } W_{g}^{s}(M)=\frac{1}{3} \int_{T}\left\langle\left(\sum_{j} \sigma_{j j}\right)\left(\sum_{k} \dot{\varepsilon}_{k k}\right)\right\rangle d t
$$

Nota: only the second term (after "and") of equation (13) must be corrected.

\section{Fatigue data}

In Table 2 there is an error in the endurance limits of fatigue test No. 4.

The correct values are $\sigma_{a}^{D}=558 \mathrm{MPa}$ (instead of 575) and $\bar{\sigma}^{D}=428 \mathrm{MPa}$ (instead of 375) with: $\tau_{a}^{D}=\bar{\tau}^{D}=0 M P a$ and $\phi=0$ degree; the REP values are correct. 